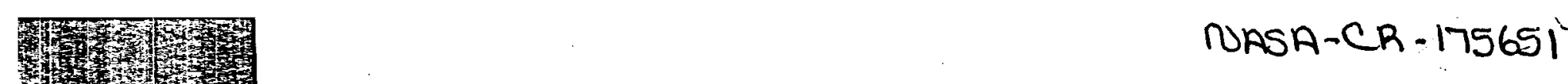

DOE/JPL/1060-81

(DE85014500)

NASA-CR-175651

19850016211

DEVELOPMENT AND TESTING OF PARABOLIC DISH CONCENTRATOR NO. 1

By

E. W. Dennison

T. O. Thostesen

December 15, 1984

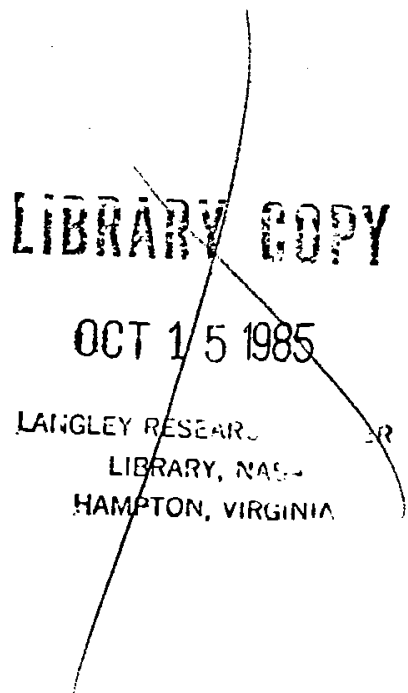

Work Performed Under Contract No. AM04-80AL13137

Jet Propulsion Laboratory

Pasadena, California

ใดำ

U15T 1985

LARGLEY RESEAROH CEMTER

LIBRARY, NASA

IAMPTON, VIRGINIS

Technical Information Center

Office of Scientific and Technical Information United States Department of Energy 


\section{DISCLAIMER}

This report was prepared as an account of work sponsored by an agency of the United States Government. Neither the United States Government nor any agency thereof, nor any of their employees, makes any warranty, express or implied, or assumes any legal liability or responsibility for the accuracy, completeness, or usefulness of any information, apparatus, product, or process disclosed, or represents that its use would not infringe privately owned rights. Reference herein to any specific commercial product, process, or service by trade name, trademark, manufacturer, or otherwise does not necessarily constitute or imply its endorsement, recommendation, or favoring by the United States Government or any agency thereof. The views and opinions of authors expressed herein do not necessarily state or reflect those of the United States Government or any agency thereof.

This report has been reproduced directly from the best available copy.

Available from the National Technical Information Service, U. S. Department of Commerce, Springfield, Virginia 22161.

Price: Printed Copy A03

Microfiche $\mathrm{AOI}$

Codes are used for pricing all publications. The code is determined by the number of pages in the publication. Information pertaining to the pricing codes can be found in the current issues of the following publications, which are generally available in most libraries: Energy' Research Abstracts (ERA): Government Reports Announcements and Index (GRA and I); Scientific and Technical Abstract Reports (STAR); and publication NTIS-PR-360 available from NTIS at the above address. 


\title{
Development and Testing of Parabolic Dish Concentrator No. 1
}

\author{
E.W. Dennison \\ T.O. Thostesen
}

December 15, 1984

Prepared for

U.S. Department of Energy

Through an Agreement with

National Aeronautics and Space Administration

by

Jet Propulsion Laboratory

California Institute of Technology

Pasadena. California

JPL Publication 85.4 

Parabolic Dish Concentrator No. 1 (PDC-1) is a 12-m-diameter prototype concentrator that evolved from a six-year effort to produce a unit with low life-cycle costs for use with thermal-to-electric energy conversion devices. The concentrator assembly features panels made of a resin transfer molded balsa core/fiberglass sandwich with plastic reflective film as the reflective surface and a ribbed framework to hold the panels in place. The concentrator assembly tracks in azimuth and elevation on a base frame riding on a circular track.

In 1982, PDC-1 was installed at the Jet Propulsion Laboratory's Parabolic Dish Test Site at Edwards Air Force Base, California. Initial optical testing showed that the panels did not exhibit the proper parabolic contour. After reassembly to correct this problem, further optical testing discovered thermal gradients in the panels with daily temperature changes. In spite of this, PDC-1 has sufficient optical quality to operate satisfactorily in a dish-electric system. With suggested improvements, its performance could be increased.

The PDC-1 development effort provided the impetus for creating innovative optical testing methods and also provided valuable information for use in designing and fabricating concentrators of future dish-electric systems. 


\section{ACKNOWLEDGMENTS}

The authors gratefully acknowledge the contributions of Maurice Argoud of the Jet Propulsion Laboratory to the PDC-1 optical testing and evaluation effort.

The work described herein was conducted by the Jet Propulsion Laboratory, California Institute of Technology, for the U.S. Department of Energy through an agreement with the National Aeronautics and Space Administration (NASA Task RE-152, Amendment 327; DOE/ALO/NASA Interagency Agreement No. DE-AM04-80AL13137). 
CONTENTS

I. INTRODUCTION. .................... . . 1-1

II. DESCRIPTION ...................... 2-1

A. BACKGROUND. ................... 2-1

1. Phase I Proposal Configuration.......... 2-1

2. Phase I Parametric Study . . . . . . . . . 2-2

3. Phase I Preliminary Design. . . . . . . . 2-2

4. Phases II and III............. 2-4

B. DESIGN REVIEWS AND DETAIL DESCRIPTION . . . . . . . 2-4

1. Interim Design Review ............ 2-4

2. Detail Design Review. ........... 2-5

C. COST REDUCTION REDESIGN ............. 2-8

III. FABRICATION AND ASSEMBLY .............. . . . . . . .

A. FABRICATION .................... 3-1

B. ASSEMBLY AT THE PDTS ........................ 3-

C. TECHNOLOGY ASSESSMENT . . . . . . . . . . . . 3-9

IV. OPTICAL TESTING . . . . . . . . . . . . . . . . 4-1

A. OPTICAL MODEL REQUiREMENTS ................. 4-1

B. image measurement techniques .............. . . 4-1

c. PANel testing Program ............... 4-2

D. OFF-SUN IMAGE TEST PROGRAM. ............. 4-2

E. ON-SUN IMAGE TEST PROGRAM ............... 4-3

F. Conclusion. . . . . . . . . . . . . 4-6

v. REFERENCE .......................... 5-1 


\section{Figures}

2-1. Model of the GE 12-m-Diameter Concentrator . . . . . . 2-5

2-2. Facility for Fabricating LCC Panels . . . . . . . . 2-11

2-3. Inner First-Article Panel ............. 2-11

3-1. Trial Assembly of PDC-1 structure ........... 3-2

3-2. Assembly of Ribs to Check Panel Fit .......... 3-2

3-3. Assemb1y of PDC-1 at the PDTS . . . . . . . . 3-4

3-4. Dish Assembly Positioned over Base Frame by Crane . . . . 3-6

3-5. PDC-1 Assembled Concentrator: (a) Front View;

(b) Rear View . . . . . . . . . . . . 3-8

4-1. Setup for Diagnostic Testing of PDC-1: (a) Colored

Target Mounted in the Concentrator Focal Plane;

(b) Telescope Located $600 \mathrm{~m}$ from Concentrator . . . . . 4-4

4-2. Diagnostic Photographs of PDC-1 . . . . . . . 4-5 


\section{SECTION I}

\section{INTRODUCTION}

Parabolic Dish Concentator No. 1 (PDC-1) is a prototype point-focusing solar concentrator that evolved from the Low Cost Concentrator (LCC) project. This project began six years ago as part of the U.S. Department of Energy (DOE)/Jet Propulsion Laboratory (JPL) program to develop a solar concentrator with low life-cycle costs for use with thermal-to-electrical power conversion systems. The project has been significant because of the knowledge gained about this approach to concentrator development and the analytical, design, and testing procedures that can be used to facilitate the development of point-focusing solar concentrators.

The development of cost-effective solar concentrators requires a combination of technology development and the application of effective commercial practices. This report discusses some of the technology and engineering aspects of concentrator development that were not clearly understood at the beginning of the project. The role of geometric optics will be described in some detail because of the increasing importance of this field of technology.

The evolution of optical analysis techniques was a direct result of the testing and performance evaluation requirements of this project. In retrospect, it is clear that the project would have proceeded more efficiently if these techniques had been used during the early stages of the project. Optical studies of solar concentators that preceded this project served as powerful tools to indicate the critical areas of design and to give accurate predictions of concentrator performance. However, these studies did not have the advantage of direct comparison with existing concentrators and components or the confrontation of problems with testing and diagnosing the imperfections of optical components as was possible in the PDC-1 project. 



\title{
SECTION II
}

\author{
DESCRIPTION
}

\section{A. BACKGROUND}

The LCC solicitation issued in April 1978 was to create the first generation of point-focusing solar concentrators specifically designed for low 1 ife-cycle costs when used in solar power conversion modules. The LCC was to be designed to generate thermal energy at $927^{\circ} \mathrm{C}\left(1700^{\circ} \mathrm{F}\right)$ in a receiver for use in a high efficiency Brayton-, Stirling-, or Rankine-cycle engine located at the focal point. The LCC was to operate in $48-\mathrm{km} / \mathrm{h}(30-\mathrm{mi} / \mathrm{h})$ winds at temperatures of -29 to $60^{\circ} \mathrm{C}\left(-20\right.$ to $\left.+140^{\circ} \mathrm{F}\right)$, survive a $161-\mathrm{km} / \mathrm{h}(100-\mathrm{mi} / \mathrm{h})$ wind and withstand rain, snow, ice, hail, and earthquakes for the 30-year lifetime of the module.

The LCC program consisted of three phases. Acurex, Boeing, and General Electric conducted parallel five-month Phase I studies consisting of a parametric study to determine the most cost-effective values for the design parameters for that company's proposed LCC configuration, followed by a preliminary design based upon these parameters. Phase II, the detailed design of the LCC, originally was to be conducted by two of the three Phase-I contractors. Phase III, fabrication, erection, and test of three LCC prototypes, was to be performed by one contractor from Phase II. Due to budgetary constraints, Phases II and III were combined. Following evaluation of proposals submitted after Phase I, General Electric was selected for the Phase II/III contract.

\section{Phase I Proposal Configuration}

GE's proposed concept for the LCC program was an injection molded plastic concentrator based upon GE's experience with the Shenandoah concentrator, a 7-m-diameter concentrator with stamped aluminum petals. This concentrator tracks the sun with a polar mount articulation system driven by screwjacks. Each Shenandoah concentrator has a receiver mounted at the focal point to warm a heat transport fluid, which is piped to a central cogeneration unit for generation of electricity and to supply thermal energy to an industrial plant.

GE estimated that the cost per unit area for the LCC must be one-third that of the Shenandoah concentrator in order to meet the mass-production cost target of the LCC program. This reduction in cost would require a design tailored for fabrication by automated factory equipment and minimal use of field labor for the erection and assembly of the concentrator. The concentrator cost would then be primarily a function of material costs. This means that the design should be lightweight and use low-cost materials. For example, the reflective surface would be either metallization of the panel front face or a metallized plastic film rather than glass mirrors, which were estimated to cost five times as much. The $20 \%$ reduction in reflectance would be offset by the lower cost. 
GE proposed a 7-m-diameter concentrator mounted on a concrete pedestal with a polar mount articulation configuration driven by jackscrews. The reflector was composed of a central hub and 12 radial petals. The hub and petals were injection molded structural foam plastic with integral ribbing on the backside. The front surface of the hub and petals was a gel coat, which was subsequently coated with vapor-deposited aluminum and then protected by a clear overcoating. To minimize labor costs, the dish would be assembled in the field with pins, splines, and clips with no field alignment or adjustment required. In high winds, the concentrator would be stowed facing the zenith while the normal stow orientation for nighttime would be facing slightly below the horizon to minimize the condensation of dew on the reflective surfaces.

\section{Phase I Parametric Study}

During the parametric study, GE determined that a focal length/ diameter ratio ( $f / D)$ of 0.5 and solar tracking and reflective surface accuracies both of $1 / 8$ deg would be optimum from a cost viewpoint. The proposed LCC configuration was reviewed, and an alternative foundation and dish configuration was selected. The original hub and petal dish did not readily accommodate the power conversion assembly (PCA) support structure loads introduced at the edge of the dish; an auxiliary metallic structure would have been required to support the PCA struts. Therefore, the dish construction was revised to incorporate panels supported on eight radial ribs located in front of the dish. The panels would be an integral part of the structure, carrying loads between the ribs as a membrane. The dish support became a tubular trusswork riding on a track around the perimeter of the foundation, supporting the dish at two diametral points on the dish rim. The result of the reconfiguration was that the greatly stiffened dish was capable of being stowed facedown and the loads were distributed over the foundation. The concentrator could be counterbalanced, minimizing the drive motor size, the loads, and parasitic power requirements. The PCA would be easily accessible from the ground. Finally, the reflective surface would be protected in stow position from direct impact by hail and dirt buildup. It was recognized that the immediate effect was to increase cost. However, the cost impact would be reduced as the engineering design of the revised concept was developed.

\section{Phase I Preliminary Design}

The front-braced, edge-pivoted configuration was refined during the preliminary design portion of Phase $I$. The dish was made of 16 panels arrayed in two concentric rings, with each panel attached along the radial edges to the rear surfaces of the radial ribs. The ribs were designed of aluminum to match the coefficient of thermal expansion of the panels, which were to be made of glass-fiber-reinforced epoxy. The front surface of the panels would be a gel coat to give a smooth surface that would not show glass fiber print-through. The gel coat would be covered by a second-surface metallized polyester film for the reflective surface. Metallization of the gel coat itself was discarded due to the uncertainty of developing the process within the program schedule. GE conducted accelerated life tests on candidate plastic films and selected Llumar film (produced by the Martin Plastics Company) as having the best 
properties over several years! exposure. Llumar film is a polyester film that is dyed with a UV (ultraviolet light) inhibiter and metallized by Martin Plastics. The dye reduces the reflectance to $82 \%$. The accelerated life screening included UV, thermal cycling, high humidity, abrasion resistance, and ability to be cleaned.

The panel fabrication concept was to stretch the plastic film over the convex (front face) half of the panel mold and spray the back side of the film with gel coat. The glass fiber mat would be positioned over the film, the mold closed, and the epoxy injected into the mold cavity. The cured panel would require only trimming to be ready for use. The thickness of the panel and the backside integral ribbing for the 7-m-diameter concentrator would be a function of minimum manufacturing process thickness rather than of structural requirements. A $1-m$-diameter test specimen was fabricated using hand layup of epoxy fiberglass on the gel-coated back surface of a plastic reflective film stretched over a spun formed mandrel. The test article had high specularity and accurately replicated the mandrel. Unfortunately, the mandrel contour was not smooth due to the spinning process; thus, the optical figure was poor. The hand layup did not duplicate the proposed fabrication process.

The original jackscrew drives were changed to cable drives in both elevation and azimuth. The elevation cable lay in a channel on a constant radius C-ring while the azimuth cable lay around the outside of the I-beam track. The large radius of the cable drive gave increased stiffness to the drive system and improved the resolution and sensitivity of the motor controls.

The foundation was designed as an I-beam track supported on pilings. The concentrator was supported on six wheels running on the track. Rotation was about a central pintle bearing. The pintle was designed to resist all lateral environmental loads while the wheels supported or resisted the vertical loads.

The tracking and control system was based upon the Shenandoah system. This system used ephemeris calculations to roughly track the sun. Fine control was provided by four fiber optic sensors mounted at the cardinal points around the receiver aperture. The concentrated solar beam was centered on the aperture by balancing the energy seen by the fiber optic sensors. The concentrator pointing direction was monitored with angular position sensors mounted on the azimuth and elevation axes. Each concentrator had its own concentrator control unit (CCU) mounted on the base structure. The CCU computed the ephemeris prediction and compared this with the readings of the angular position indicators. Whenever the actual-to-predicted of $f$ set exceeded a hysteresis limit value, the drive motors would run until the of nulled out. The concentrator would then remain immobile until the of $f$ set error again was excessive. This on/off system was used to reduce parasitic power. When the sun tracker system was being used, the sun sensor logic would actuate the drive motors whenever the imbalance between opposing sensors reached a threshold value. During fine control, the ephemeris system would continue to function, serving as a backup and taking over in case of loss of sun tracker control during, for example, passage of a cloud's shadow. A central computer would provide control inputs to all ccUs and monitor the performance of all the concentrators in a field. The drive motors had dual speeds, updating the sun pointing at low speed and slewing on and of $f$ sun at high speed to prevent solar overheating of the engine, receiver, or concentrator components. 
During the preliminary design phase, GE reviewed the parametric study and predicted that the cost per unit area would be minimized for a diameter of 9 to $11 \mathrm{~m}$.

4. Phases II and III

GE submitted their Phase II/III proposal based upon the Phase I results. A diameter of $10+1 \mathrm{~m}$ was proposed to reflect the optimal minimum cost sizing and to match the power requirements of engines and receivers being developed under parallel programs for use in solar power modules. JPL negotiated the contract on the basis of an 11-m-diameter concentrator. The contract was later modified for development of a $12-m$-diameter dish that would provide the same thermal performance as an $11-\mathrm{m}$-diameter test bed concentrator (TBC) utilizing glass mirrors.

\section{B. DESIGN REVIEWS AND DETAIL DESCRIPTION}

\section{Interim Design Review}

The 12-m-diameter concentrator design presented at the interim design review had 36 reflective panels arranged in three concentric rows of 12 panels, each supported at the radial edges along the rear surface of 12 radial ribs (Figure $2-1$ ). The ribs were to be made of aluminum to match the coefficient of thermal expansion of the glass-filled epoxy panels. The attachment of the panels to the ribs was being investigated with the goal of rapid self-alignment in order to minimize field assembly labor. The proposed panel fabrication method was resin transfer molding (RTM) for prototype units and resin injection molding (RIM) for high-production units.

GE also studied the use of glass mirrors bonded to a panel substrate as a higher performance reflective surface. However, this effort was terminated because of possible problems of stress in the glass and of differences in coefficients of thermal expansion that might degrade optical performance.

Screening and development tests on the plastic reflective film continued. The application of a hard coat over the film for weathering and abrasion protection was pursued. Panel molding feasibility tests determined that it was impractical at that time to try to mold a panel while the plastic film was already in the mold. The film alone, or even when backed by a gel coat, suffered severe "orange peel" due to the flow of the resin while filling the mold and the softening of the film and gel coat due to the exothermic reactions during resin cure. Attempts to directly bond the film to the molded panel surface were unsatisfactory, as glass fibers in the panel surface would print through the film. The panel surface had to be extremely smooth (requiring frequent mold repolishing), and bonding to a concave three-dimensional surface is quite difficult. It was decided to laminate the film to a smooth plastic sheet, 0.1 to $0.15 \mathrm{~cm}(0.040$ to $0.060 \mathrm{in.})$ thick. This would eiminate print-through and mold polishing and would greatly simplify the application to the panel. Life testing indicated that the plastic reflective film would require replacement once during the 30-year design life. 


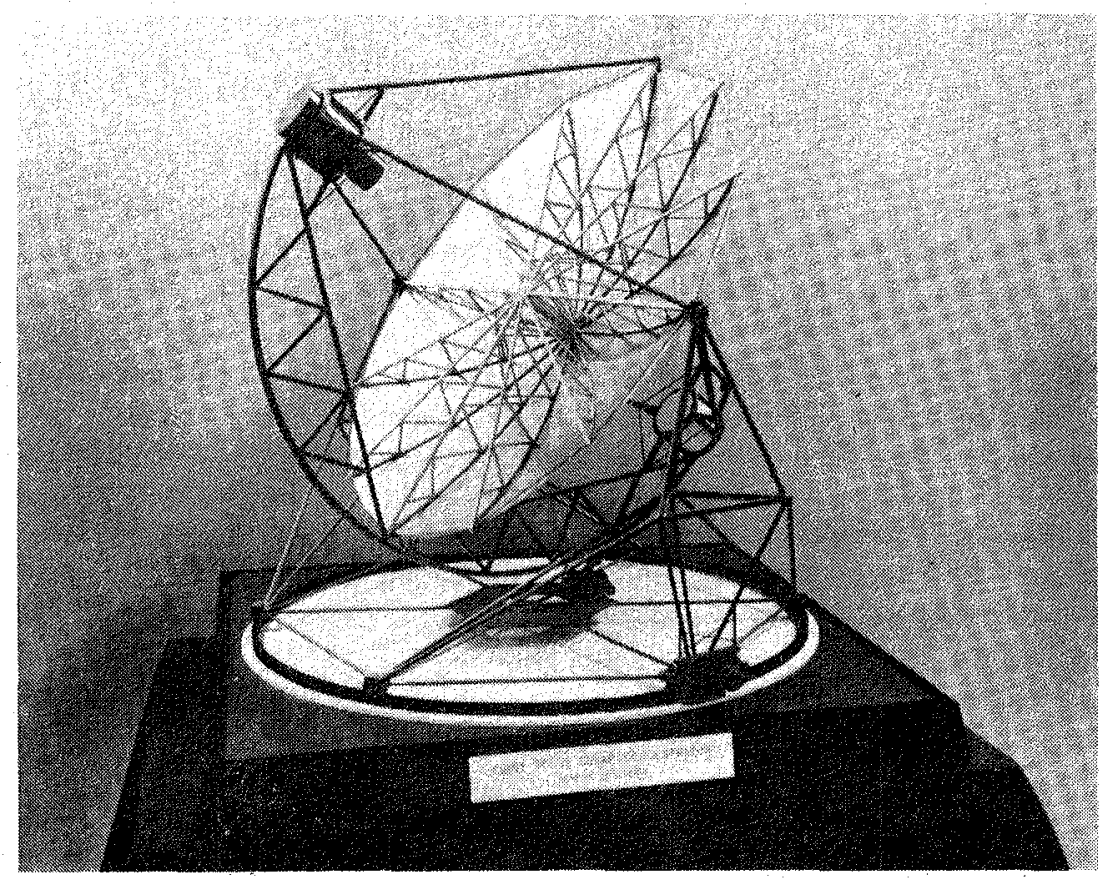

Figure 2-1. Mode1 of the GE 12-m-Diameter Concentrator

GE developed a detailed NASTRAN structural analysis model for predicting loads, stresses, and deflection for use in the structural and optical analysis. The NASTRAN (structural) and POLYPAGOS (optical) results for the design as it existed at the interim design review showed that the limiting structural condition was exposure to a $97-\mathrm{km} / \mathrm{h}(60-\mathrm{mi} / \mathrm{h})$ wind while in any orientation. Some structural members were overloaded in buckling, and the end fittings of the dish ribs were overstressed. The POLYPAGOS optical analysis, utilizing the NASTRAN structural deflection predictions for a $48-\mathrm{km} / \mathrm{h}(30-\mathrm{mi} / \mathrm{h})$ wind, showed that the outer reflective panels were too flexible in bending. The corresponding intercept factor would be $85 \%$ rather than the desired $96 \%$. The panels had become stiffness-sensitive as opposed to manufacturing-minimum-thickness limited as in the $7-\mathrm{m}$ case.

\section{Detail Design Review}

Following the interim design review, GE modified the design of the concentrator to correct the strength and stiffness problems discovered. The panel required a four-fold increase in stiffness to raise the optical intercept factor to the $96 \%$ goal. This was first attempted by increasing the numbers and depth of the integrally molded backside stiffening ribs. The $5.1-\mathrm{cm}\left(2-\mathrm{in}_{\text {. }}\right)$ deep ribs on $15.2-\mathrm{cm}\left(6-\mathrm{in}_{\text {. }}\right)$ centers significantly increased the panel weight, and concern was expressed that such a panel might be difficult to release from the mold following cure. Because plastic resin is expensive, the weight increase had cost implications. A molding vendor suggested a resin transfer molded (RTM) balsa core/fiberglass sandwich construction used widely 
in the small boat building industry. This was investigated and adopted. The advantages realized by the balsa core panel over the integrally cast rib panel are a weight reduction of $50 \%$, elimination of sink marks on panel surface over stiffening ribs, reduction of panel warpage that would result from molding parts with ribs on only one side, and substantial reduction in mold tooling costs due to the simplified mold cavity.

The balsa core panel utilizes two polyester fiberglass skins, which are separated by an end grain balsa wood core. The balsa core is supplied as a mat of $5.1-b y-5.1-\mathrm{cm}(2-b y-2-i n$.$) blocks bonded to a fiberglass scrim cloth$ with balsa fibers aligned perpendicular to the scrim cloth. This configuration allows the mat to drape over curved surfaces and aligns the balsa grain to give maximum sandwich compression strength. The sandwich panel is molded by (1) loading the mold cavity with a layer of glass fiber matting, the balsa core, and a second layer of glass fiber matting, (2) closing the mold, (3) injecting the polyester resin, and (4) curing at a controlled temperature. When the resin is injected, all voids in the mold (including those between the balsa blocks) are filled. The resin does not fill up the balsa tubular grain because the balsa cells are interrupted periodically by membranes. This construction method forms the panel as an integral piece with negligible molding springback because of the uniform temperature during cure and the balanced fiberglass-balsa-fiberglass cross section.

The panel attachment to the ribs had to precisely position and lock the panels on the ribs. The design evolved into a tongue-and-groove configuration. Aluminum extrusions were to be bonded to the radial edges of the panels. The grooves in these extrusions engaged ridges on the back edges of the ribs. The panels were clamped onto the ribs by a strap across the gap between panels. All mating parts would have to be curved to the desired parabolic figure.

The use of an abrasion-resistant coating on the plastic film was further investigated and finally discarded. The protective coating would not adhere to the film during accelerated weathering testing.

The tooling for molding the panels was started. A $2.1-b y-3.4-\mathrm{m}$ (7-by-11-ft) air bag press was designed to constrain the molds during the RTM process. This press was considered to be the largest in the U.S., capable of making parts measuring up to $3.2 \mathrm{~m}^{2}\left(34 \mathrm{ft}^{2}\right)$. Three molds were required, one each for the inner, middle, and outer panels. The mold fabrication method was to fabricate a panel master and then build up the mold from the master. The master was built up by sweeping a parabolic blade template, mounted on an arm at the correct radial distance and orientation, across a master base fixture. (This blade is initially used for sweeping plaster into a parabolic surface.) The blade is then used to sweep a final thin epoxy layer over the plaster. The final configuration of the master is a replica of the desired panel, including both front surface and proper thickness edges, sitting on a curved "pallet" surface. The front mold halves were made from the masters by replicative buildup starting with a gel coat and fiberglass layups. The back mold halves were made by filling the front mold cavities flush with spacers, covering with a smooth sheet, and replicating this surface.

The base framework was designed to be tubular members with left- and right-hand threaded end fittings for the prototype concentrators. The threaded end fittings allowed member lengths on the prototype LCCs to be 
adjusted during baseframe setup and alignment by simple rotations of the tubes with the fittings acting as turnbuckles. The end fittings were attached to clevises on weldments at each tube intersection. The base rotated the pintle on six captured wheels running on an I-beam track. The wheels were designed for 4219-kg (9300-1b) down loads and 1633-kg (3600-1b) uplift. The pintle is designed for $9078-\mathrm{kg}(20,000-\mathrm{lb})$ side loads and 454-kg $(1000-1 \mathrm{~b})$ uplift. The track was bedded on a concrete pad, which was sized by the uplift loads on the track due to winds. The fcundation for the prototype installed at the

Parabolic Dish Test Site (PDTS) also included the requirements for conduits and piping for instrumentation wiring, cold water calorimeter water supply and return, pressurized nitrogen gas, domestic water, and fuel for a hybrid-cycle receiver (that burns fuel when no sun is available).

The drive systems for azimuth and elevation were passed around two drums slaved together by a chain. The elevation drive pulled on a cable tied down to the dish C-section for elevation motion. The azimuth drive pulled itself along a cable anchored at each end on the track for azimuth motion.

The control system for centering the concentrated solar energy on the aperture was changed from the Shenandoah fiber optics system to a sun sensor directly facing the sun. The fiber optics would be unable to survive the high energy flux while slewing on and of sun. The Shenandoah concentrator had experienced some early developmental problems with heating at the lower solar intensities generated by that system. The original intent for control system development was to modify the Shenandoah circuit boards to satisfy the LCC requirements. For example, the heat transfer fluid control logic was not needed for the LCC. Unfortunately, the Shenandoah program schedule slipped, and its circuit boards would not be available in time for use on the LCC. Therefore, GE undertook the development of LCC controls at their facility in Valley Forge, Pennsylvania, utilizing available software logic. This resulted in considerably more effort, expense, and time than originally planned.

The LCC control system was tailored for use with the three LCCs to be installed at the PDTS as part of the contract. The central computer was to be able to control all three units simultaneously. Each concentrator would have an individual control panel located in the control building. The control panel was to display the azimuth and elevation resolver readings directly without relying on the central computer. The individual control panel was to have provisions for manually controlling drive motor operation by speed, direction, and on/off. The control panel was to have provision for inputting commands for a specific LCC to the central computer by means of push-button input. The central computer could accept direction from the manual control panels, the central computer terminal, or from a user's system computer.

The CCU contained a manual drive control panel in parallel with the control panel in the control building. The CCU contained the logic for ephemeris calculation and comparison to the resolver readings, the translator for sending the resolver readings to the control panel, the sun sensor logic, and logic for sending commands to the motor controllers.

The control system was designed to command the concentrator to go to any of three fixed positions, one of which is stow (facing down). The concentrator can track the sun by ephemeris calculations to within $0.3 \mathrm{deg}$, by 
sun sensor control to within $0.1 \mathrm{deg}$, or offset from the sun in both axes by selectable amounts. The offset position can be used for standby or as a verification of proper controller operation before going on sun. The concentrator control system will immediately react to detrack or panic signals by driving down and east at the $2 \mathrm{deg} / \mathrm{s}$ slew speeds for nominally $10 \mathrm{~s}$ to move the focussed solar beam away from the engine/receiver and LCC structure. After detrack timeout, the LCC sits dormant until a detrack reset is input into the central computer. The detrack signal could originate by (1) manually pushing a button on either the CCU or manual control panels, (2) loss of communication between the computer and CCU, (3) external signal from the engine/receiver control computer, or (4) a resolver/ephemeris difference that exceeds a threshold level (nominally $1 \mathrm{deg}$ ).

The POLYPAGOS optical performance prediction for the stiffened LCC as presented at the detail design review was $98 \%$ for a $31.1-\mathrm{cm}(12.25-\mathrm{in})-$. diameter receiver aperture.

\section{COST REDUCTION REDESIGN}

Following the detail design review, GE conducted an internal company assessment of the LCC and concluded that the design was too heavy and costly to meet the program's economic goals. In making the LCC more rigid to increase the intercept factor from 85 to $98 \%$, the weight had increased significantly. Therefore, GE redesigned the LCC to make it more economically viable. The design requirements and specifications were reviewed in detail to isolate the dominant cost drivers, and adjustments were made where reasonable.

The LCC was originally intended for use with any of the "highefficiency" heat engines being developed under other contracts. Therefore, the design requirements specified a receiver temperature of $927^{\circ} \mathrm{C}\left(1700^{\circ} \mathrm{F}\right)$ for use in calculating thermal efficiencies. The LCC design receiver temperature requirement was reduced to $816^{\circ} \mathrm{C}\left(1500^{\circ} \mathrm{F}\right)$, which was the original engine inlet temperature desired. This lower temperature was still conservatively high because the LCC was to be used with the organic Rankine-cycle (ORC) engine at $427^{\circ} \mathrm{C}\left(800^{\circ} \mathrm{F}\right)$ and would probably not be used at higher temperatures.

The wind requirements of survival in stow at $161 \mathrm{~km} / \mathrm{h}(100 \mathrm{mi} / \mathrm{h})$, withstanding $97 \mathrm{~km} / \mathrm{h}(60 \mathrm{mi} / \mathrm{h})$ in any orientation, operation in $48-\mathrm{km} / \mathrm{h}$ $(30-\mathrm{mi} / \mathrm{h})$ winds, and $100 \%$ thermal performance at $35 \mathrm{~km} / \mathrm{h}(22 \mathrm{mi} / \mathrm{h})$ were reviewed. Subsequently, the stow survival wind speed was reduced from 161 to $145 \mathrm{~km} / \mathrm{h}(100$ to $90 \mathrm{mi} / \mathrm{h})$, which corresponds to heliostat specifications and experience with environmental conditions at the JPL Edwards Test Station where the PDTS is located.

The wind survival requirement of $97 \mathrm{~km} / \mathrm{h}(60 \mathrm{mi} / \mathrm{h})$ in any orientation, which was the limiting structural load condition, was reduced to $80 \mathrm{~km} / \mathrm{h}$ $(50 \mathrm{mi} / \mathrm{h})$ in view of the fast LCC slew speeds and the ability to manually override the control system when high winds are imminent. The requirement for operation in $48-\mathrm{km} / \mathrm{h}(30-\mathrm{mi} / \mathrm{h})$ winds remained unchanged. Finally, the wind velocity at which $100 \%$ performance was to be measured was reduced from 35 to $24 \mathrm{~km} / \mathrm{h}$ ( 22 to $15 \mathrm{mi} / \mathrm{h}$ ) based upon statistical data of wind speed versus time on sunny days. 
GE reviewed the design of the LCC and concluded that it would be costeffective to reduce the optical efficiency slightly, giving rise to large reductions in weight and cost. Enlarging the receiver aperture used in the performance calculations from 30.8 to $33.2 \mathrm{~cm}(12.12$ to $13.12 \mathrm{in}$ ) allowed the structural stiffness requirements to be relaxed. For example, the panel thicknesses could be tailored to fit the loads; the inner and middle panel balsa core thickness was set at $1.27 \mathrm{~cm}(0.5 \mathrm{in.})$ and the outer panel core thickness was $2.54 \mathrm{~cm}$ ( 1 in.).

The reduction in wind loading requirements on the panels allowed the panel-to-rib attachment to be greatly simplified. The type of joint presented at the detail design review was a tongue-and-groove configuration with a total metallic cross section, $26.2 \mathrm{~cm}^{2}$ ( 4 in. ${ }^{2}$ ) per $\mathrm{rib}$, made of aluminum extrusions. The panel edges were to be reinforced with higher density wooden inserts. (This feature was subsequently deleted from the design.) The reduced panel loadings allowed a simple system of knurled $13.1-\mathrm{cm}^{2}$ $\left(2-i n .^{2}\right)$ blocks clamping the panels to the rib, relying upon friction to hold the panels in place. The clamp restraint system was experimentally tested to verify that the panels would not move under the expected loads. The rib face was changed from an extrusion, with integral grooves for capturing the tongues on the panel edges, to a simple hat section.

The rib material was changed from aluminum to steel because of the large cost difference per pound between steel and aluminum stock. This was recognized as increasing the sensitivity of the thermal performance of the LCC to temperature changes, but the NASTRAN/POLYPAGOS analytical model predicted that the variations were tolerable. The rib construction was changed from trusswork web stiffening to solid corrugated webs. The corrugation construction was thought to require less factory labor.

The base structure framework configuration was modified by elimination of two support wheels and the addition of diagonal braces between the pintle and the two tetrahedral structures supporting the elevation bearings. The two elevation bearings were self-aligning roller bearings capable of resisting axial thrust loads with no end play. This configuration was statically determinate with minimal net vertical reaction at the pintle. The original configuration required one elevation bearing for axial compliance because any track irregularities would cause the opposite halves of the base to vary the distance between the elevation bearing mounting points. As a result, all lateral loads would have been carried by a single bearing.

The slew speed drive rate was reduced from 2.0 to $1.7 \mathrm{deg} / \mathrm{s}$. This allowed the use of a 2-hp dc electric motor and a less expensive gear reducer. The motor torque and gear reducer ratio were set by the requirement to slew in a $80-\mathrm{km} / \mathrm{h}(50-\mathrm{mi} / \mathrm{h})$ wind while in any attitude. The slightly reduced slew speed was considered adequate to prevent damage to the PCA and structure while going on and off sun.

As a result of the GE redesign, the LCC estimated weight per unit area was reduced $28.5 \%\left(172\right.$ to $\left.123 \mathrm{lb} / \mathrm{m}^{2}\right)$, and the estimated mass-production cost was reduced $40.5 \%\left(370\right.$ to $\left.220 \$ / \mathrm{m}^{2}\right)$. Increasing the aperture diameter by $5.1 \mathrm{~cm}$ ( $2 \mathrm{in.}$ ) and reducing the intercept factor by $1 \%$ were the corresponding penalties. 
Following the period of redesign, program costs were reassessed and were found to be escalating significantly. Therefore, the contract was modified to reduce the number of prototypes from three to one. Subsequently, GE was instructed simply to complete all drawings, fabricate the first-article panels, and complete the development of the control system.

The panel development leading to the first-article panels included molding of flat test specimens to determine panel fabrication techniques and strength properties, fabrication of the molds and air bag press, tests to verify the adequacy of the panel-to-rib mounting system, and methods of bonding the reflective surface to the panel. The fabrication facility is shown in Figure 2-2. The first-article panels (Figure 2-3) were the first successful reflective panels made from each of the three (inner, middle, and outer) molds. These three panels were delivered to JPL for optical evaluation to verify the mold acceptability.

Flat panels, 0.61 by $1.2 \mathrm{~m}$ ( 2 by $4 \mathrm{ft}$ ), were molded using RTM to provide specimens for measuring material properties versus skin and core thickness and for panels to be used in edge restraint and thermal distortion testing.

The three panel masters were fabricated by System Resources of Boston, Massachusetts, and shipped to Design Evolution 4 (DE4) in Lebanon, Ohio. DE4 built the molds from the masters as described previously.

The air bag press, used to constrain the molds during the RTM process, and the mold handling carts were fabricated. Experience in the operation of the press and fine tuning of the RTM process were accomplished by molding test parts, $3.8 \mathrm{~cm}(1.5 \mathrm{in.})$ thick, using a mold based upon two side-by-side Shenandoah panels. The resultant panel had a parabolic contour with greater curvature than an LCC panel but roughly the same surface area. These test parts served to refine the RTM polyester injection techniques and to provide experience in loading the molds and in molding and curing large panels. The test panels were also used in the development of techniques for installing the reflective surface on the panels.

GE calculated the worst case edge loads on the panels, based upon environmental conditions, using the NASTRAN computer model. Flat panel specimens were subjected to tensile and moment loadings in a simulation of the proposed clamping rib/panel attachment. The specimens showed the least restraint capability at low temperatures due to panel shrinkage in relation to the steel bolts. GE concluded from the test data that the panel edges, when clamped, acted as fixed joints and that the load capability was sufficient to resist the anticipated loads.

The application of the reflective film to the panel surface required substantial development as identified at the interim design review (II.B.1). It was decided to laminate the reflective film onto $0.15-\mathrm{cm}(0.060-i n$.)-thick plastic sheet material and bond the laminate to the panel. The sheet plastic would provide a smooth surface for the film and would mask small imperfections in the panel face, allowing the mold to be used without repolishing. The process of applying the reflective surface was, thus, similar to that required for glass mirrors but much easier -- because the plastic conforms to the panel compound curvature without danger of fracture. The method selected for 


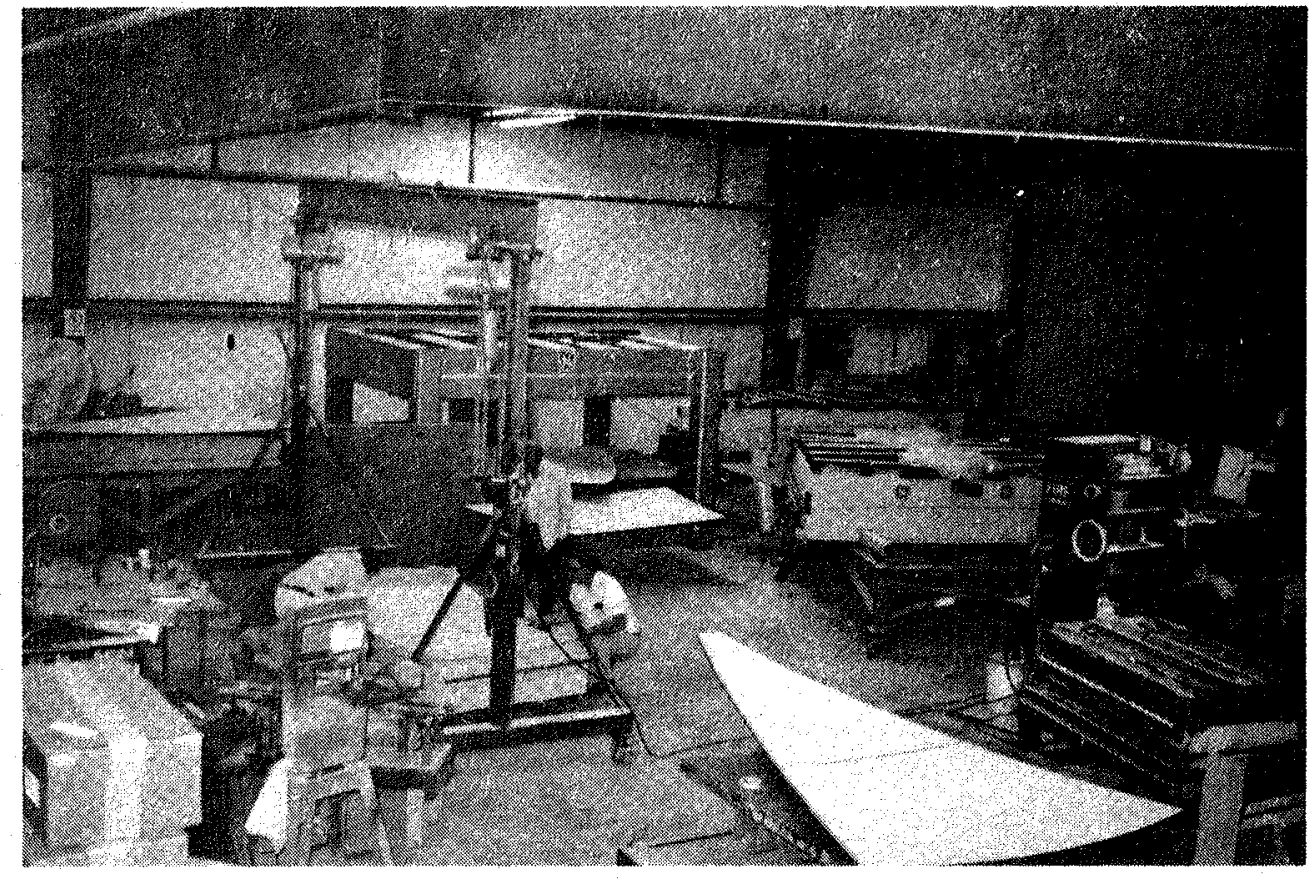

Figure 2-2. Facility for Fabricating LCC Panels

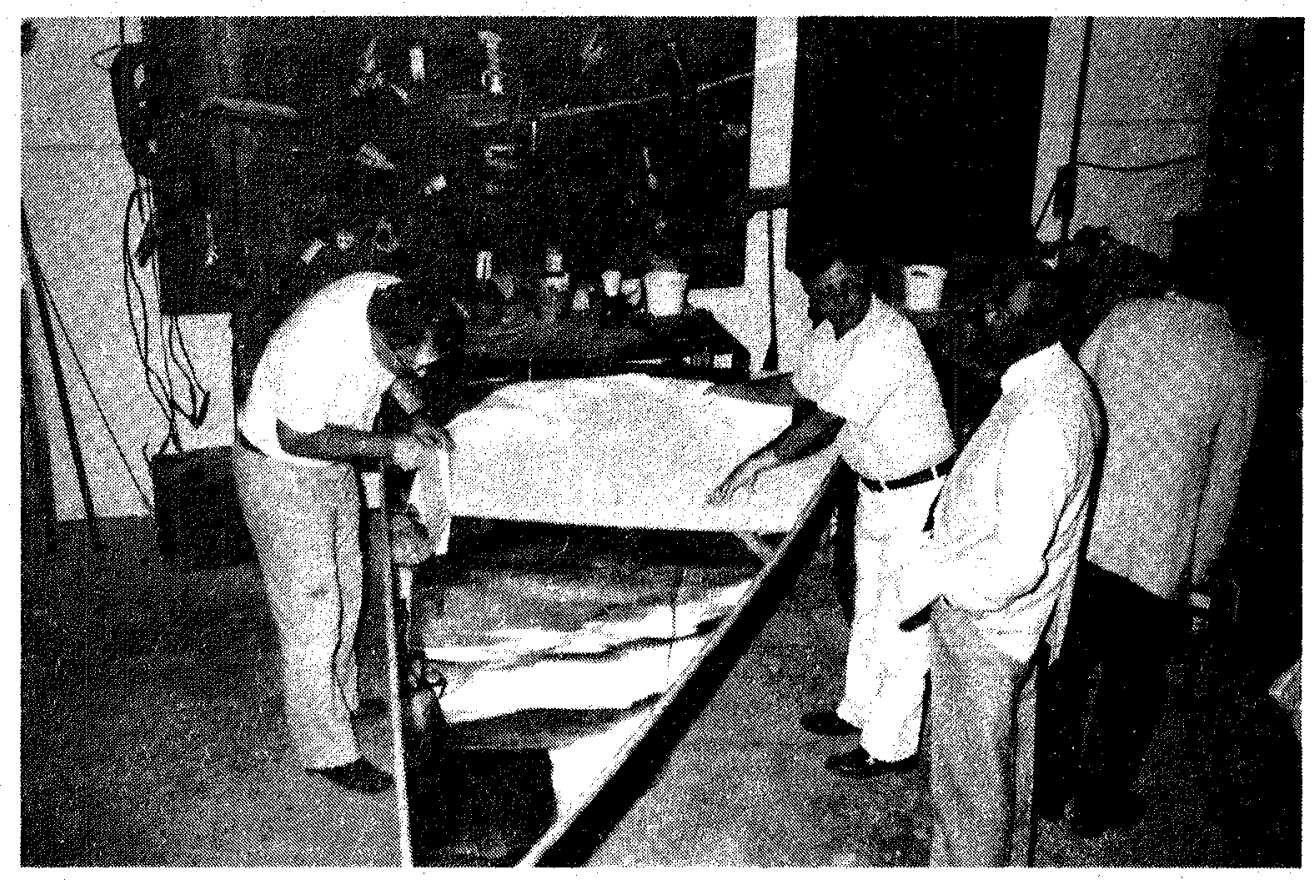

Figure 2-3. Inner First-Article Panel 
attachment of the laminate to the panel was contact cement. The contact cement was sprayed on both the panel face and the back of the laminate and allowed to dry. The reflective laminate was bonded in place by pressing the laminate against the panel while one side of a folded layer of polyethylene film was pulled out from between the laminate and panel to progressively expose the contact cement.

The first-article panels were molded relatively easily. The molds were completely filled. The primary reason for remolding additional parts was that adjustments were made to the shims between the mold halves to give the desired fiberglass skin thicknesses of $0.216 \pm 0.013 \mathrm{~cm}(0.085+0.005 \mathrm{in.})$. The reflective $\mathrm{film}$ and $0.15 \mathrm{~cm}(0.060-\mathrm{in}$.) Plexiglas-DR sheeting were more of a problem. The llumar film roll obtained from the vendor had a reflectance of $79 \%$, which was at the lower limit of the GE material specification. The material also had a mottled pattern of reflectance. This roll of film was used because it met the reflectance specification and because schedule constraints precluded replacement. The Plexiglas-DR, extruded by Southern Plastics, had been selected based upon a preliminary sample. Thin material, such as the $0.15-\mathrm{cm}$ thickness, is difficult to extrude without a repetitive pattern of varying thickness. This is controlled by selection of extrusion temperature and by slowing the extrusion speed. The Plexiglas-DR run for the LCC prototype was delivered with an unacceptable ripple thickness variation. The material was rerun and was much more uniform although the concentrator reflective surface does exhibit a faint pattern of stripes. The Llumar film was laminated to the Plexiglas-DR sheets by Raymond Engineering in Canada. The laminate was covered on both faces by protective film. The protective film was removed from the Plexiglas-DR prior to application of the contact cement. The protective film was left on the Llumar film until the panels were used on the LCC.

The control system development continued with the procurement and buildup of the first CCU and manual control panel and with the generation of the CCU and central computer software. JPL supplied the LSI-1103 central computer. The LSI-1103 caused some initial concern because a board was replaced before delivery to GE, thereby upgrading the system to an 1123 . This created problems with the software. Therefore, the original board was reinstalled. However, communication problems between the CCU and the LSI-1103 persisted until Digital Equipment Corporation (DEC), the LSI-1103 manufacturer, generated a fix. The dilution of effort due to the LSI-1103/CCU communication problem, in addition to the loss of some GE personnel, caused funding for the controls to be exhausted before the control system was completed, debugged, or fully documented. With shipment to JPL of the first-article panels and the hardware/software for the control system (as it then existed), the contract with $G E$ was closed out. 
FABRICATION AND ASSEMBLY

With the close of the GE contract, the ICC project was terminated, but the concentrator designed under the project was selected for use with the organic Rankine-cycle (ORC) module as part of the small community systems experiment to be installed at Osage City, Kansas. Ford Aerospace and Communications Corporation (FACC), system integrator for the experiment, was directed to fabricate a prototype unit for installation at the JPL Parabolic Dish Test Site (PDTS) in order to gain experience in building this concentrator.

Because the projected cost of the LCC exceeded the original mass-production goal, the name "LCC" was dropped. Around the same time, a decision was made that a series of concentrators, having the potential for commercialization, would be developed by the TPS Project. The GE-designed concentrator became the first in this series and was, hence, designated "Parabolic Dish Concentrator No. 1" (PDC-1).

\section{A. FABRICATION}

In December 1981, FACC subcontracted with Alco Machine Company of Birmingham, Alabama, to fabricate the prototype PDC-1 structure, with Ashland Engineering of Lancaster, California, to install the foundation, and with Valley Iron of Lancaster, California, to erect the structure. Alco had also fabricated and installed the two TBC structures for E-Systems at the PDTS. The structural components for PDC-1 were shipped to the PDTS in March 1982. The concentrator base structure was trial assembled and aligned at Alco prior to shipment (Figure 3-1). All tube member lengths were set and locked by jam nuts, and mating parts were marked prior to disassembly. The dish ribs were assembled into the re ector array and precisely positioned (Figure 3-2). The parts were match dril 1 and marked. The first-article panels had been sent to Alco and were fit cuecked to the ribs. Valley Iron was represented at Alco during the trial assembly to gain familiarity with the hardware.

Upon arrival of the structural components at the PDTS, it was discovered that some tubes were damaged and most of the preset lengths were changed. During the trip, the driver of the truck noticed that the tubes were vibrating badly. Upon inspection, he found that most end fitting lock nuts had loosened and that many end fittings had backed out of the tubes. Some end fittings were lying loosely on the bed of the trailer and two were missing. The driver gathered up the loose parts and cinched the load down hard using chains. Some of the tubes arrived with permanent bows and two had dimpled areas due to crushing by the chains. The missing end fittings were replaced and the damaged tubes judged to be usable. The member lengths had to be reset during assembly at the PDTS. 


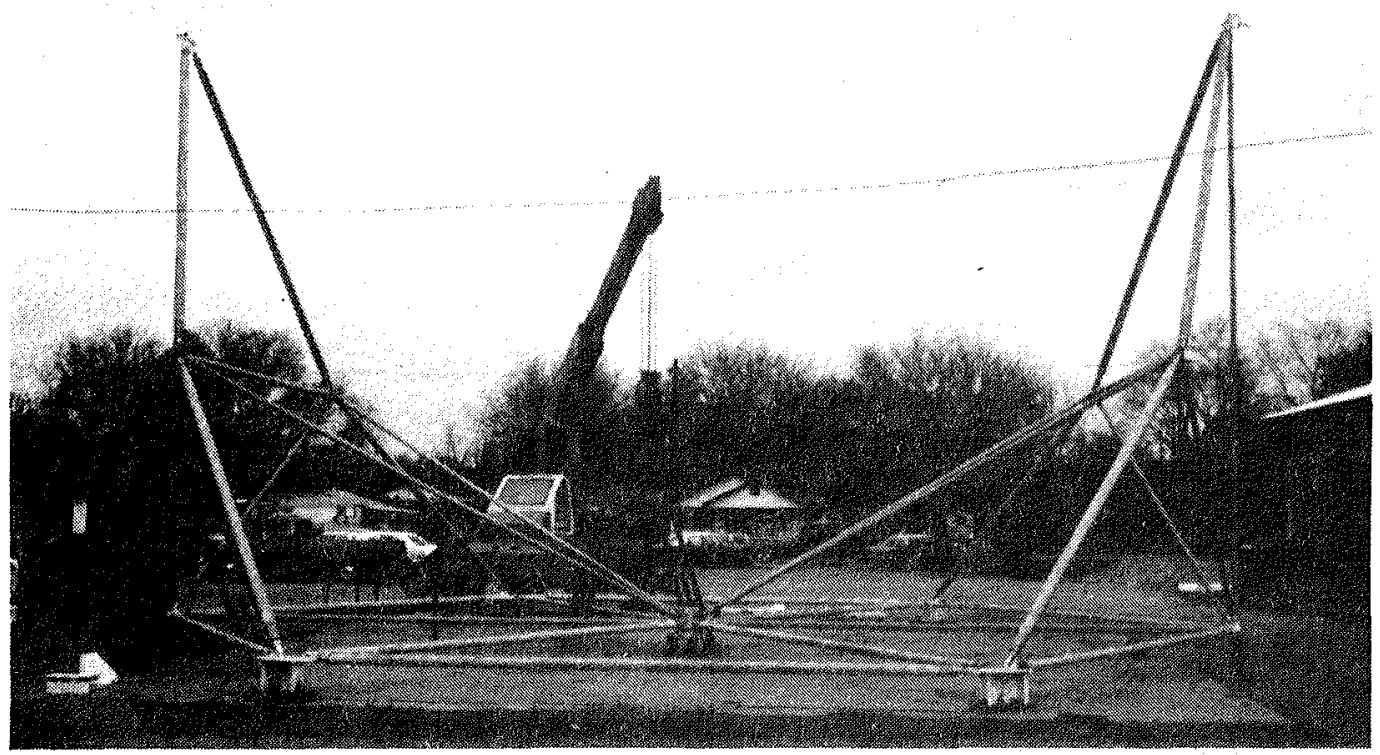

Figure 3-1. Trial Assembly of PDC-1 Structure

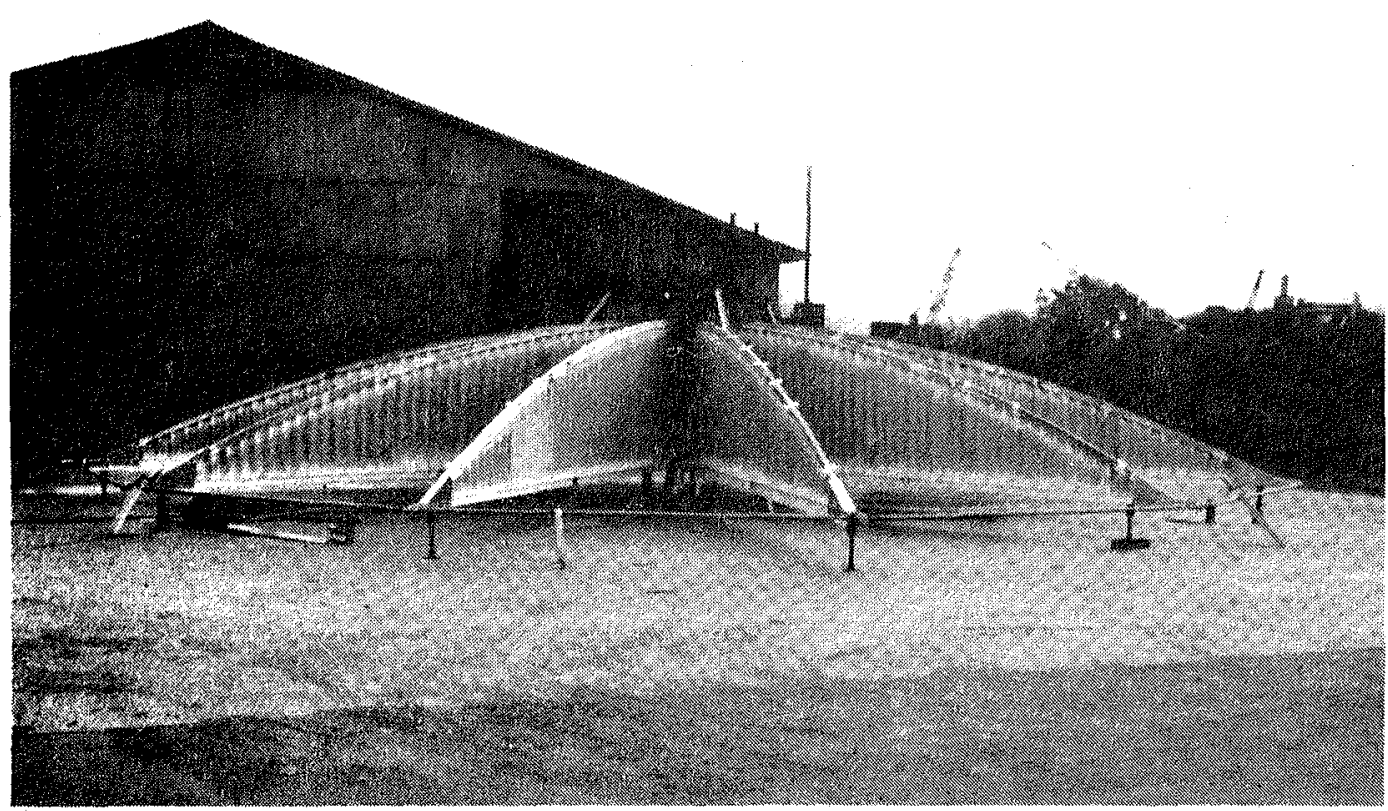

Figure 3-2. Assembly of Ribs to Check Panel Fit 
The foundation was a central pintle concrete monolith pier circled by 28 concrete posts, upon which the steel I-beam track was set. The track was in seven segments, joined by splice plates on the inside of the track web. The track was welded at each post to small plates that were adjusted vertically by double nuts on the four studs. The track was positioned to be concentric to the pintle within $0.64 \mathrm{~cm}(0.25 \mathrm{in.})$ and level within $0.317 \mathrm{~cm}(0.125 \mathrm{in.})$. The top flange of the rail was welded and ground smooth at the joints. The pintle bearing was set on the studs of the central pier and adjusted vertically by double nuts.

The base framework was assembled on the track as shown in Figure 3-3. The three support wheels and the azimuth drive with the fourth wheel were positioned on the track and tied together (using radial members) to the pintle and the chordal members between the ends of the radials. The two elevation bracing support tetrahedron frameworks were preassembled and 1 if ted into position. Finally, the diagonals between the tetrahedron and the pintle bearing were installed.

The reflector structure was assembled facedown on blocks close to the foundation (see Figure 3-3). The 12 ribs were bolted together after the relative heights and 30 -deg spacings were established. The rib end chordal tie rods and midspan brace straps were installed. The panels were then positioned on the ribs and clamped in place using the knurled blocks. It was noticed during panel installation that the panels had a finite difference in coefficient of thermal expansion relative to the steel ribs. The $3.05-\mathrm{m}$ $(10-f t)-10 n g$ inner panels were positioned on the ribs and restrained only by clamp blocks at the inner ends of the panels. The next morning the panel length was found to have shrunk $0.317 \mathrm{~cm}(0.125$ in.) relative to the ribs due to the overnight temperature drop. The panels returned to the original length relative to the ribs as the day warmed.

The reflector assembly was set on blocks beside the foundation and baked in the sun. It was soon discovered that certain panels were moving on the ribs. Typically, one side of these panels would slip sideways under all of its clamp blocks, retracting toward the edge of the rib at night and partially returning during the day. This ratcheting action walked the panel of $f$ of the edge of the rib where the panel would drop down slightly. Upon heating the following day, the panel would jam against the side of the rib and arch. Recentering the panel on the ribs did not solve the problem, which was probably due to uneven spacing of the ribs circumferentially and to improper centering of the individual panels. All panels were removed, the rib spacing adjusted, and the panels carefully reinstalled. The backs of the panels were painted to reduce panel temperature relative to the structure. The panels still moved -- with only one panel/rib interface slipping in each circumferential row of panels. It was as if all strain buildup in a row was relieved at a single interface. The torque of the bolts in the clamp blocks was increased to raise the clamping force, but the only effect was that some inserts began to be pulled out of the ribs.

It was decided to review the loads imposed on the panel joint. Consequently, JPL reviewed and updated the NASTRAN model to reflect the PDC-1 hardware, including such changes as thicker middle and outer panels and 


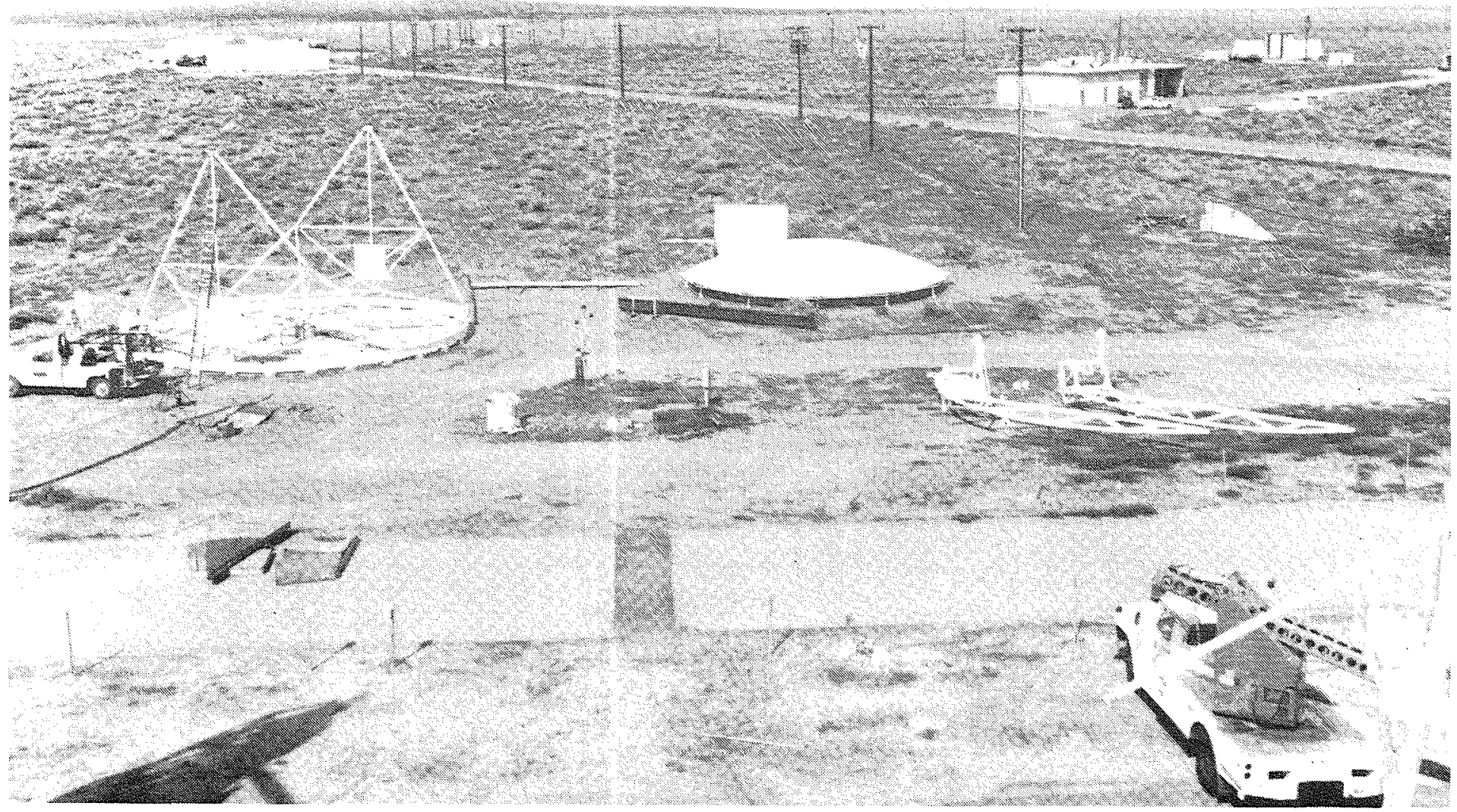

Figure 3-3. Assembly of PDC-1 at the PDTS. (Base framework assembly on track is on the left; reflector structure facedown on blocks is on the right.) 
revised weight estimates. In addition to the structural load cases run by GE, JPL investigated the loads for an asymmetric $145-\mathrm{km} / \mathrm{h}(90-\mathrm{mi} / \mathrm{h})$ survival wind and for an asymmetric earthquake (aligned along the elevation axis). Unfortunately, these two cases proved to be the limiting load cases for both the base structure and the dish.

The base structure was found to have negative margins of safety in buckling during an earthquake for the vertical and horizontal members of the tetrahedron supporting the elevation axis. The diagonal braces from the tetrahedron to the pintle had positive but inadequate margins. The tetrahedron structures were modified by adding braces to the centerpoints of the vertical and horizontal struts to increase their buckling load capabilities.

The struts supporting the engine/receiver frame and the counterweight frame were removed and larger diameter center sections installed to increase their buckling resistance design margins.

The dish loads were set by the asymmetric $145-\mathrm{km} / \mathrm{h}(90-\mathrm{mi} / \mathrm{h})$ survival wind loads. The NASTRAN model breaks each panel into four radial and six circumferential areas. The tension and bending loads are computed for the midpoints of each area. The midpoint loads had to be interpolated first circumferentially and then radially to obtain the load distribution along the panel/rib interface. The loads obtained at the panel corners were an order of magnitude greater than the GE values. GE had averaged the loads along the edge of each panel; in contrast, JPL tailored the attachment spacing to the calculated load distribution. It was felt that the load values predicted by JPL at the corners might be high due to the interpolation process and the coarseness of the model but that the total loads were much higher than originally predicted. The observed panel behavior due to daily temperature swings alone showed that the designed panel restraint was inadequate.

It was decided to restrain the panels by bolts loaded in shear rather than to rely upon friction. The panels were removed from the ribs, and $1.9-\mathrm{cm}$ (0.75-in.)-diameter steel bushings were bonded into holes bored $2.54 \mathrm{~cm}$ ( 1 in.) from the edge of the panel. The number and spacing of the inserts was dictated by the calculated loads along the edge of the panels. Nineteen inserts were used on each radial edge of the inner panel, 15 inserts on the middle panel, and 11 inserts on the outer panel.

The ribs were modified to accept the new panel attachment method. A $9.5 \mathrm{~cm}(3.75 \mathrm{in.})$ wide by $0.25 \mathrm{~cm}(0.1 \mathrm{in.})$ thick steel strap was riveted onto the parabolic rear edge of the ribs to provide the flat surface to which the panels would be bolted. The thicknesses added by the steel strap and the flange on the panel bushing were considered to have a negligible effect on the concentrator optics.

The panels were installed by drilling bolt holes in the rib straps after the panels were positioned properly, using the panel bushings as drill guides. The panels were then bolted to the ribs using a total of $10800.64-\mathrm{cm}$ (0.25-in.) bolts. The panels were now indeed integrated into the dish structure. The panels were installed in August 1982 during temperatures peaking at $42^{\circ} \mathrm{C}\left(108^{\circ} \mathrm{F}\right)$. 
The dish assembly was prepared for transfer onto the base structure by the installation of the preassembled counterweight support framework onto the rear of the dish. The assembly was then lifted by a crane and positioned over the base frame as shown in Figure 3-4. The PCA support framework had been previously assembled and placed inside the base structure, elevated slightly. The dish was lowered until the PCA support framework engaged the dish mating fittings and these attachments were made. The temporary fixture holding up the PCA support framework was then removed and the dish lowered further until the elevation bearings contacted their mating surfaces on the base structure. The elevation bearing housings were then bolted to the base structure.

The rotation about the elevation axis was verified using the crane to offset the weight imbalance. A concrete weight to simulate the PCA was installed at the dish focal point, and counterweights were added in $4.5-\mathrm{kg}$ (10-1b) increments to the rear and side of the structure to balance the system about the elevation axis. The drive cables were then installed, and operation in elevation and azimuth was verified. The cable routing around the two drive drums was not workable as designed because the cable would walk across the flat drum to the side flange and then cross over itself. The drive drums were modified by a center divider to separate the cable wraps.

It was noticed that misalignment of the base support wheels was causing the azimuth motion to be punctuated periodically by side slips of the wheels on the track. The wheels tended to follow a spiral path around the pintle.

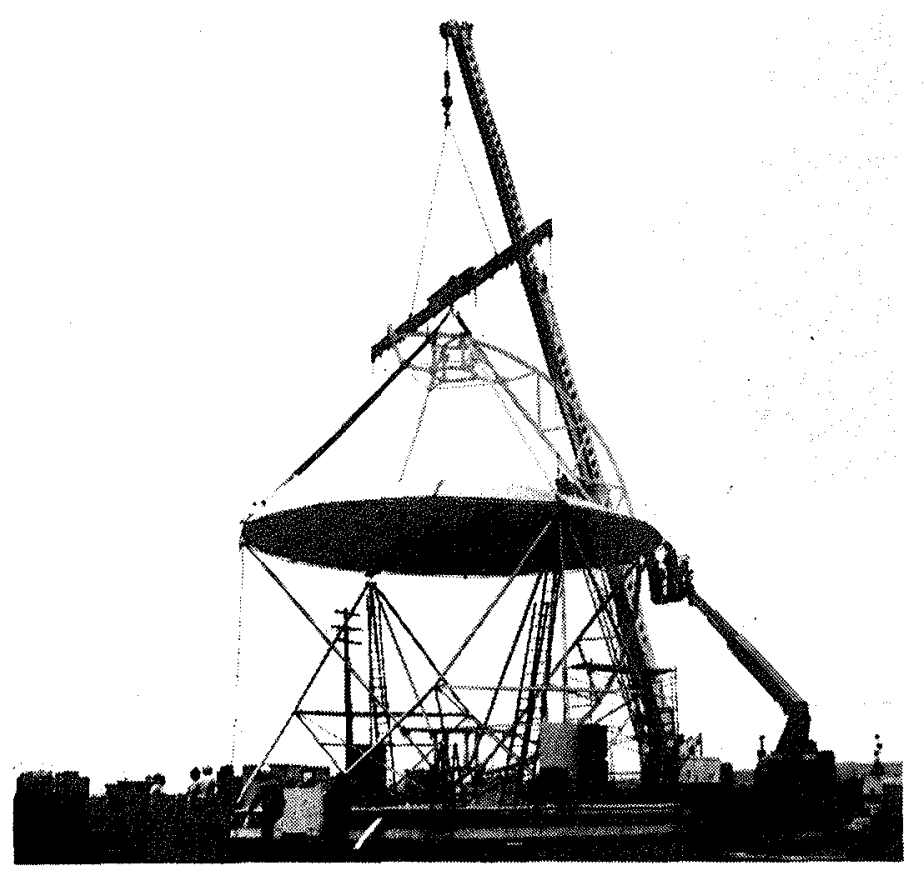

Figure 3-4. Dish Assembly Positioned Over Base Frame by Crane 
The side forces generated by the misalignment caused adjacent radial struts to bow due to the moments imposed on the wheel housings. When the stored energy reached a threshold, the wheel would slip sideways on the rail to relieve the load. The wheel alignments were adjusted, improving but not totally eliminating the condition.

The wheel bearings proved to be severely overloaded and required replacement. The original bearing arrangement was a caged set of long rollers running on the axle as an inner race and a chevron split steel sleeve pressed into the wheel as an outer race. The bearing is protected by grease seals, which feature integral washers to provide axial constraint. After a short period of operation, the concentrator azimuth motion showed distress, with the cable slipping on the drive and the motor controller requiring higher settings to move in azimuth. Grease was injected into the wheels, and it was found that two of the wheels would not accept grease.

The wheels were jacked up to check for rotational freedom. A pry bar was required to turn the wheels. The axle nuts were backed off to remove axial pre-load. The wheels could then be rotated by hand. Later, the wheels again became bound; the axles were pulled to allow inspection of the bearings. All of the wheel bearings were damaged, ranging from heavy wear to disintegration. The bracing under the 454-kg (1000-1b) azimuth drive showed the most damage: The roller cage was broken, and the split sleeve had been severely cold worked and partially extruded out the end of the wheel housing. The axles also showed wear, but the rollers were undamaged. Four new wheels with higher capacity tapered roller bearings were obtained and installed.

Following initial optical testing ${ }^{1}$ of the assembled concentrator (Figure 3-5), it was decided to demount the dish and reposition the panels with the correct parabolic contour to improve the optical performance. An interesting trait of a paraboloid is that any plane parallel to its axis will cut the paraboloid in a parabola identical to the one used to generate the paraboloid. Therefore, tooling was made that could measure the deviation of the panel from the true parabolic shape, using dial indicators as the sensing system. The panels were moved $1.27 \mathrm{~cm}(0.5 \mathrm{in.})$ outboard along the ribs to permit drilling the new attachment holes into the straps in virgin material. The panels were made to arch in the desired parabolic contour using (1) steel banding that spans the width of the panel and (2) small, precision scissorstype, adjustable-height jacks at the midpoint, thus causing the panel to bend like an archery bow when the string is drawn back. Two measuring tools and band/jack setups were used simultaneously to set each panel curvature at both the inner and outer edges. All panels in one row where arched in sequence until all were stable and correct while the ambient and panel temperatures were nominally 13 to $16^{\circ} \mathrm{C}\left(55\right.$ to $\left.60^{\circ} \mathrm{F}\right)$. All bolt holes in that row of panels were to be drilled and the bolts installed while the temperatures remained in that range. The $13-t o-16^{\circ} \mathrm{C}\left(55-t o-60^{\circ} \mathrm{F}\right)$ temperature range was selected for minimal thermal distortion during daytime operation in the following few months. It was difficult to implement the setting of the panel

${ }^{1}$ Described in Section IV. 


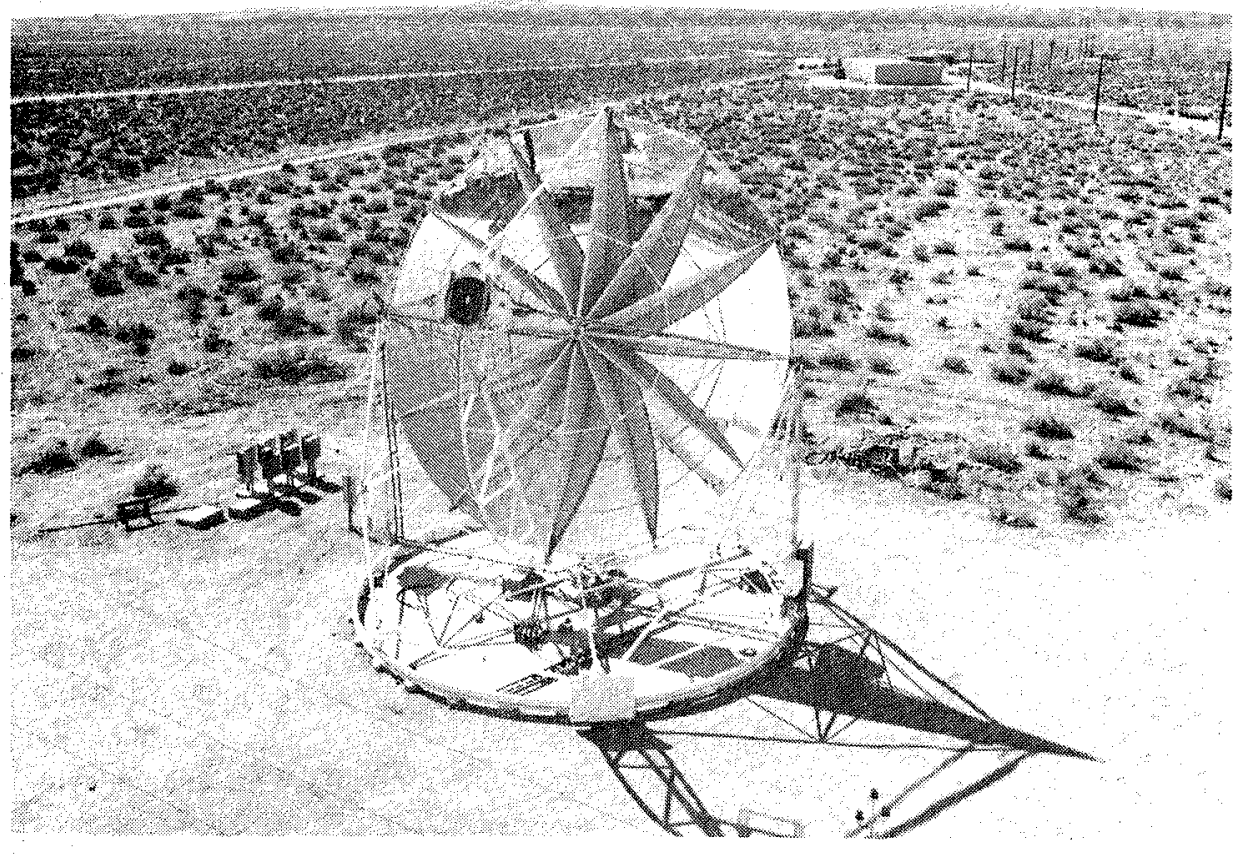

(a) Front View

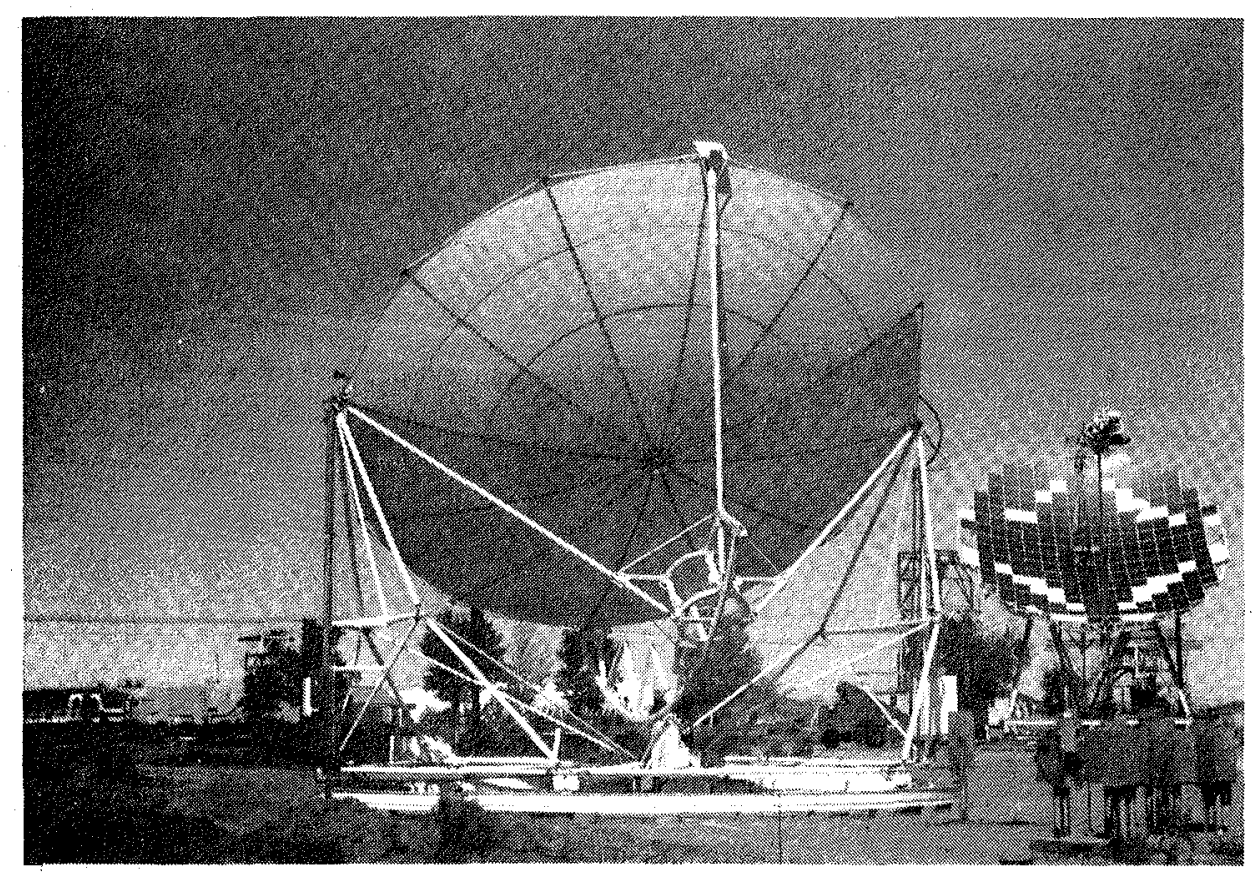

(b) Rear View

Figure 3-5. PDC-1 Assembled Concentator 
arches and drilling and installing the bolts while the temperatures were within the desired range. Temperatures at night were around $30 \% \mathrm{~F}$ and rose rapidly after sunrise. Working furiously, a crew of ten was able to drill and install the bolts for one row of panels in one hour. This was repeated on three successive mornings.

The dish was lifted back onto the base framework 15 days after it was taken down. Optical testing (see Section IV) showed that the image on the focal plane for the $5.6-\mathrm{km}(3.5-\mathrm{mi})$ distant light source had been reduced from 76.2 to $25.4 \mathrm{~cm}$ (30 to $10 \mathrm{in.})$ in diameter - a significant improvement. Further optical testing revealed some temperature dependence, but PDC-1 was now optically acceptable.

While the dish was on the ground for panel adjustment, the four spare panels in each row were substituted for the most seriously delaminated panels. The reflective laminate had shown a tendency to bubble or separate locally from the panel substrate. One theory is that this problem was caused by inadequate evaporation of the volatiles in the contact cement prior to placing the reflective laminate on the panel. The remaining volatiles would collect and form a bubble. Holes were drilled through the laminate to the bubble to vent the gas pocket. In about one-half of the cases, pressing the bubble flat resulted in elimination of the bulge. The Llumar film separated from the Plexiglas-DR at the edges of a few panels near the steel inserts, but this is not as prevalent a condition as the delamination from the panel.

It was immediately obvious by comparison of the spare panels with the remaining original panels that the latter had taken a permanent set after being under tension for 2-1/2 months. The older panels required much more arching effort to be set in the parabolic shape. This suggests that the optical performance would probably be improved over the $25.4-\mathrm{cm}$ (10-in.)-diameter obtained if all panels were new because in the present configuration the old panels will try to flatten out and push against the adjacent new panels so that old panels will be flatter than desired and new panels will have exces arch.

\section{TECHNOLOGY ASSESSMENT}

PDC-1 has had many birthing problems, but this is to be expected of a new design when first built. The general impression of those who have worked with the PDC-1 prototype is favorable. PDC-1 is aesthetically pleasing to the eye. The rear of the reflector is smooth, not having the multitude of beams and struts typically bracing a microwave antenna. The base framework of tubular members is lightweight and logical from an engineering viewpoint.

The ability to invert the reflector for stowing has many virtues. The dish is stowed edge on toward wind blowing from any direction. The typical solar concentrator, such as the TBC, faces north during idle periods to prevent the sun from striking the reflective surface and causing heating due to glint. The structure could be massive (like the TBC) to survive high winds or the reflector could be pointed toward the vertical for reduced wind resistance, but the typical dish would then be vulnerable to overheating of the PCA supports due to glint on a windy, clear day. The facedown stow position also 
protects the reflective surface from hail impact and minimizes dirt buildup during periods when the concentrator is not in use. The PCA, in a facedown stow, is moved close to the ground, thus allowing access by simple platforms rather than requiring a cherry picker or man hoist. Facedown stow also allows the PCA to be lowered vertically into the PCA support, if desired, rather than put in horizontally while the dish faces the horizon as with the TBCs.

PDC- 1 is balanced around the elevation axis by the addition of counterweights on the rear structure. This reduces the motor and gear reducer torque requirements. The cable drive, with its large radius of action, is very stiff and capable of moving the concentrator precisely. The stop/start control system has demonstrated a sun tracking accuracy of \pm 0.05 deg. The stop/start drive using small motors has lowered the parasit $\bar{i} c$ power usage.

The placement of the ribs in front of the reflective surface greatly reduces the glint problem because the solid corrugations intercept the sun's reflections harmlessly. The reflector has proved to be very stiff and has exhibited no flutter problems. In a $48-\mathrm{km} / \mathrm{h}(30-\mathrm{mi} / \mathrm{h})$ wind, the focal hot spot shows virtually no motion caused by deflections of the structure or panels.

The use of large panels integrated into the dish structure potentially can reduce the field labor required for assembly and makes the supporting steelwork less extensive and massive.

PDC- 1 does have some less favorable features. However, these could be ameliorated by redesign based upon experience with the prototype. For example, the foundation is very massive and costly. The track is supported on 28 concrete posts buried several feet in the ground while the pintle bearing sits on a central concrete pillar. The ground inside the rail is paved with concrete to provide a hard, easily maintained surface to facilitate testing of the concentrator. The foundation should be reviewed prior to installation at each site to determine the most economical way to support the track and pintle.

The pintle contains a self-lubricating plastic bearing, which exhibited wear that was probably due to the side load imposed by the azimuth cable tension. The pintle design also makes installation and adjustment of the azimuth axis resolver very difficult.

The cable drive windlass pulleys, as mentioned previously, were modified by the addition of a center divider to separate the cable wraps. The steel cable ran on flat steel pulley surfaces, which is detrimental to cable life and has a low friction coefficient. This became very obvious when the stowed PDC- 1 rotated in elevation due to aerodynamic lift forces in a $48-\mathrm{km} / \mathrm{h}$ $(30-\mathrm{mi} / \mathrm{h})$ wind. A PCA support strut struck the boom of the cherry picker being used by two personnel working on the reflector. As a result of this incident, $P D C-1$ was modified by the addition of a latch pin for securing the system in elevation when stowed. The cable tension was increased and regularly checked. Later, structural damage occurred when the cable slipped on the drums due to a weight imbalance while a 454-kg $(1000-1 \mathrm{~b})$ weight was being removed from the PCA mount. The reflector rotated in elevation until the stop hit the elevation drive. The drive pulleys were then modified by the removal of the center divider and by bonding polyurethane bands with two integral cable grooves to the surface of the pulleys. This modification 
provided a higher coefficient of friction, greatly reducing the cable tension required and subsequently reducing the loadings on the pintle and elevation bearings. The elevation drive was proof tested with a 681-kg (1500-1b) lateral load on the PCA mount, with no cable slippage occurring.

The base framework has been criticized for the complexity of the weldments at the structure nodal points. This was recognized by GE at the time the concentrator was designed, but it was believed that weldments would be less expensive than castings for the three prototypes specified in the contract. The parts were to be redesigned as castings if sufficient concentrators were to be fabricated in the future. The present design of the azimuth wheel housings does not allow subsequent adjustment of the wheel alignment without altering the base framework tubular member lengths. The wheel housings should be redesigned to allow precise alignment of the wheels relative to the rail after concentrator assembly. Misalignment, such as that observed with PDC-1, causes the wheels to periodically sideslip on the track.

The design loads should be reviewed and the member cross sections adjusted to give acceptable factors of safety. In particular, an economic trade-off study should be made between heavier base frame tetrahedron vertical and horizontal members versus the center point bracing added to PDC -1 .

The reflector is susceptible to temperature changes and thermal gradients. The steel ribs have a poor mismatch of coefficient of thermal expansion with the panels and might well be made of aluminum to reduce the dish sensitivity to temperature if high thermal performance is required. The ribs were originally aluminum but were changed to steel as a cost saving. The temperature gradient through the panel when the concentrator is tracking the sun tends to flatten the panel, and methods of reducing the gradient, such as paint or backside insulation, should be explored. The Plexiglas-DR also has an expansion mismatch with the fiberglass-balsa sandwich. The Plexiglas-Llumar laminate negates one of the original advantages of the plastic film over glass: the ability to directly mold the film in the panel as opposed to bonding glass to the panel surface. The laminate also decreases the cost advantage of film versus glass. The use of glass might be investigated because the reflectance would be increased by about $15 \%$, and the surface would be more environmentally resistant.

The rib-panel attachment should be reviewed from the standpoints of both the joint design and the panel installation procedure. If the present bolted panel attachment is used, the ribs could be redesigned to combine the "riveted-on" strap with the deep curved hat section. This would result in a more accurate parabolic rib surface while simplifying the fabrication of the rib. The method of panel installation should be modified to reduce the effects of ambient temperature and gravity sag.

The inverted stow position of PDC-1 places a constraint on the PCA because care must be taken so that engine lubricants do not drain out or seep into undesirable areas within the mechanism.

The control system has a potentially dangerous characteristic: the concentrator can detrack at any time without warning while in the operational mode. The concentrator will then move at approximately $20.3 \mathrm{~cm} / \mathrm{s}(8 \mathrm{in.} / \mathrm{s})$ in both elevation and azimuth for $10 \mathrm{~s}$. 

SECTION IV

OPTICAL TESTING

One part of the technological evolution of converting sunlight into electrical power using point-focusing concentrators has been the development of optical models and testing techniques for characterizing and evaluating such concentrators. The first optical models were intended to demonstrate the feasibility of this type of concentrator and to indicate the relationship between the component characteristics and the operating performance. With these models, it was not possible to verify the operating performance until after the completed concentrator was pointed at the sun. During the development of PDC-1, there was a need for performance testing before completing the concentrator. These tests required a different approach to optical modeling and refined image measurement techniques.

\section{A. OPTICAL MODEL REQUIREMENTS}

The new optical models are designed to permit changes in the parameters that control the image characteristics. The variable input parameters should be the source size, source distance, optical surface properties, and structural displacements resulting from gravity, wind, temperature, etc. The output data should be in the form of image outlines, flux distributions, and intercept factor curves (field-of-view acceptance functions). With this type of model, it is possible to predict the image characteristics for any required test or alignment configuration. Comparison of the predictions and the measurements can be used to change the input parameters or, in some cases, the model algorithms. When an acceptable agreement between the model and the point source measurements has been made, then the model can be used to calculate the image characteristics of the concentrator when pointed at the sun. To facilitate this procedure, it is mandatory that these new models have the option of using either the sun or a point at a finite distance as a source. This interactive method of mathematical modeling and point source testing is described in detail in Reference 1.

\section{B. IMAGE MEASUREMENT TECHNIQUES}

Some of the image measurement techniques used for the PDC-1 project were modifications of the techniques used for the test bed concentrators (TBCs). The spherical surfaces of the TBC facets were tested in an autofocus mode: With a point source located at the center of curvature, the spherical surface will return a point image to the center of curvature. A paraboloidal surface, however, will only form a point image from a point source on axis at infinity. In practice, it is possible to use a point source at a finite distance.

The images can be quantitatively evaluated with aperture photometers, which measure the fraction of the image flux that falls inside or outside of a circular aperture. A plot of these data is an intercept factor curve and can be directly compared with an optical model prediction. An image scanning 
photometer also can be used to measure an image. For measurements of a solar image, a calorimeter and a flux mapper are used to make quantitative measurements of the concentrator performance.

If the rest image is substantially larger than the predicted image, it is necessary to find the source of the optical imperfections and determine the corrective action to be taken. Diagnostic images or photographs are used to distinguish between small optical surface imperfections and large-scale surface or figure errors. These diagnostic photographs have been found to be a very useful tool for determining corrective.procedures to achieve the desired concentrator performance.

\section{PANEL TESTING PROGRAM}

The first task of the optical testing project was to evaluate the firstarticle prototype panels which were delivered to JPL during the summer of 1981. The collimated light source of the $25 \mathrm{ft}$ space simulator was used to test these panels. With one lamp and one lens, the simulator beam could be characterized as a source of $0.9 \mathrm{mrad}$ angular size at a distance of $400 \mathrm{~m}$ $(1312 \mathrm{ft})$. The solar diameter is $9.4 \mathrm{mrad}$ and, therefore, much larger than the source. A small adjustment was made in the focal plane position to compensate for the finite distance of the virtual source.

A scanning photometer was used to measure the intensity distribution of the image. These data were combined into annular zones, and an intercept factor curve was fitted to the measured data points with the use of an interactive computer program. Using the new optical modeling programs developed by Trentelman (Reference 1), the measured intercept factor points could be matched to an optical model of the concentrator that used all of the nominal dimensions and a single surface slope error parameter. The surface errors were described by a Gaussian error function.

Diagnostic photographs were made of the prototype panels, and it was determined that the image errors were the result of large-scale irregularities in the reflecting surface. These irregularities were most probably the result of uneven application of the adhesive used between the acrylic sheets and the plastic panels. An attempt was made to apply the adhesive more evenly for the production panels.

When the production panels were delivered, the 25-ft space simulator was not available for panel testing, and an alternative configuration was needed. A spotlight was located on a mesa above JPL at a distance of $900 \mathrm{~m}$ ( $2953 \mathrm{ft}$ ). The images were photographed and measured with an aperture photometer. Diagnostic photographs were also made. The results indicated that the production panels were better than the prototype panels. These data were used as a baseline reference for the expected image quality of the assembled concentrator.

\section{OFF-SUN IMAGE TEST PROGRAM}

When PDC-1 was assembled for the first time, the point source image was much larger than expected. Diagnostic photographs of the type used for the 
panel tests could not be made because of the very small $\mathrm{f} / \mathrm{D}$ of the concentrator. A technique, sometimes referred to as "backgazing," proved to be very effective. This diagnostic method is based on the concept of interchanging the source and the image. The source is a colored target of either a quadrant or concentric ring pattern mounted in the focal plane (Figure 4-1a). From a distance of $600 \mathrm{~m}(984 \mathrm{ft})$, the target is viewed or photographed through a telescope (Figure 4-1b), and the size or direction of the panel errors can be determined from the shape and location of the colored areas. The first view through the telescope showed that there was a gross distortion of the panels. The quadrant pattern clearly indicated that the panels were less concave than a paraboloid, and it was believed that this was the result of excessive tension induced by the high ambient temperature at the time of pane 1 installation as described earlier in this report. To test this theory, one of the panels was remounted. The image of the target through this panel was much improved. For this and subsequent tests, a concentric ring pattern was used.

As discussed in the previous section, the concentrator panel support structure was returned to the ground and all of the panels were remounted. This was done at a lower ambient temperature with the panels forced to a paraboloidal figure. After the concentrator was reassembled, diagnostic photographs of the panels demonstrated that the image was much smaller, and the point source image was found to be about the same size as the unmounted pane 1 images.

It was feared that the difference in the thermal expansion coefficients of the plastic panels and the steel structure would be a source of serious image degradation. Diagnostic photographs over a $24-\mathrm{h}$ period as the ambient temperature changed from a low of $4.4^{\circ} \mathrm{C}\left(24^{\circ} \mathrm{F}\right)$ to a high of $24.4^{\circ} \mathrm{C}\left(76^{\circ} \mathrm{F}\right)$ (Figure 4-2) were used to evaluate the effect of this problem. The image was less than $23 \mathrm{~cm}$ ( $9 \mathrm{in.)}$ in diameter at the higher temperature, and about $5 \%$ of the image area was larger than $38 \mathrm{~cm}$ ( $15 \mathrm{in.}$ ) in diameter at the lower temperature. This indicated that the concentrator with a $38-\mathrm{cm}(15-\mathrm{in}$.) aperture would give satisfactory performance over at least a $100^{\circ} \mathrm{F}$ range. During some of the off-sun tests there were high winds, but careful examination of the diagnostic images showed that there was no detectable displacement of the concentrator or the panels. No gravity-induced deflection was visible.

JPL microwave dish computer models were used with the PDC-1 NASTRAN data as a reference for comparison with the diagnostic photographs. The agreement between photographs and the computer plots was remarkably close. The importance of this work is that it indicates that with some additional refinement it may be possible to relate the structural forms and materials directly to the optical performance of a solar concentrator.

\section{E. ON-SUN IMAGE TEST PROGRAM}

Evaluation of $P D C-1$ performance with the sun as a source was accomplished by the calorimeter testing program, which was started in January 1983. The open calorimeter $(52.1 \mathrm{~cm}$, or $20.5 \mathrm{in.})$ showed that the overall thermal output power of PDC-1 was $72.5 \mathrm{kWt}$ normalized to an insolation of $1 \mathrm{~kW} / \mathrm{m}^{2}$. The intercept factor measured by the calorimeter through a $38-\mathrm{cm}$ (15-in.) aperture stabilized at less than 0.90 , which is substantially 


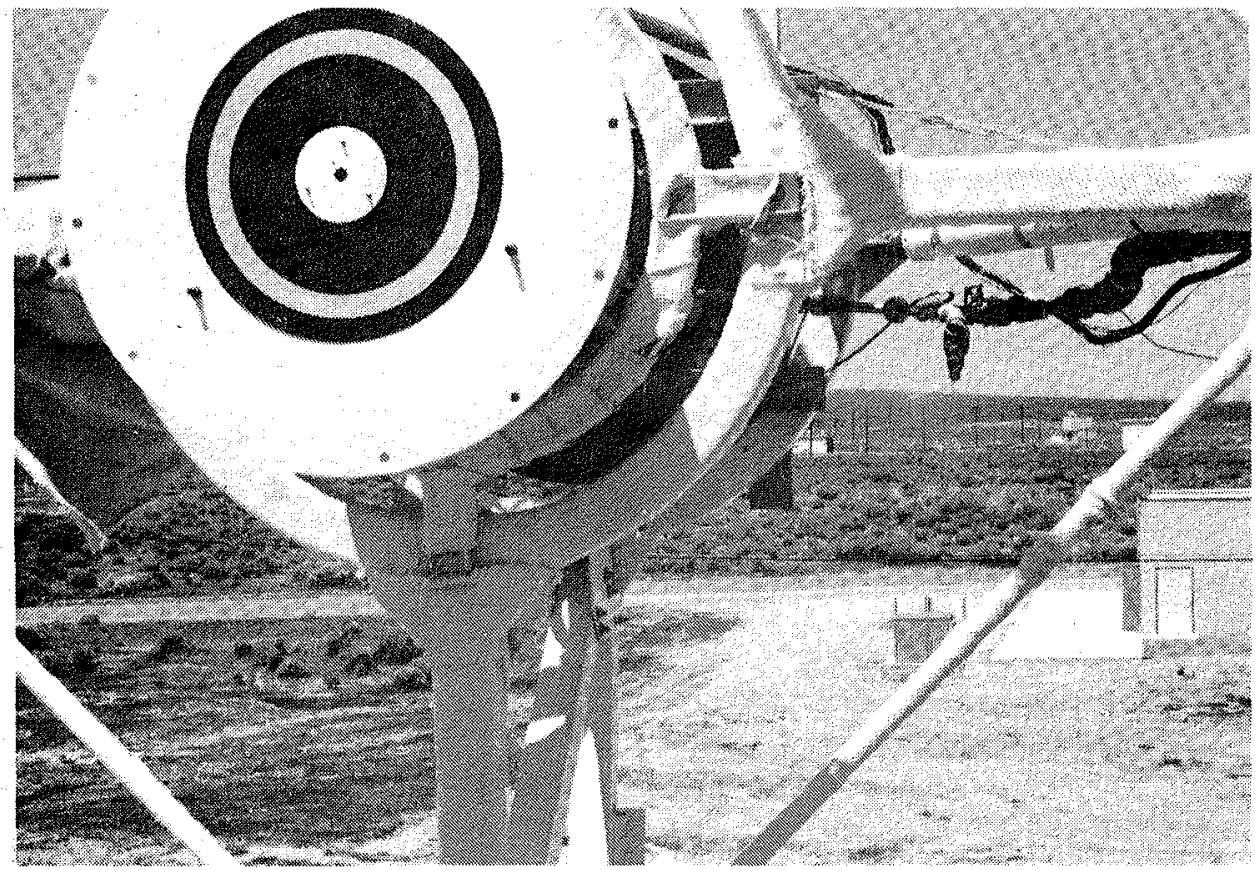

(a) Colored Target Mounted in the Concentrator Focal Plane

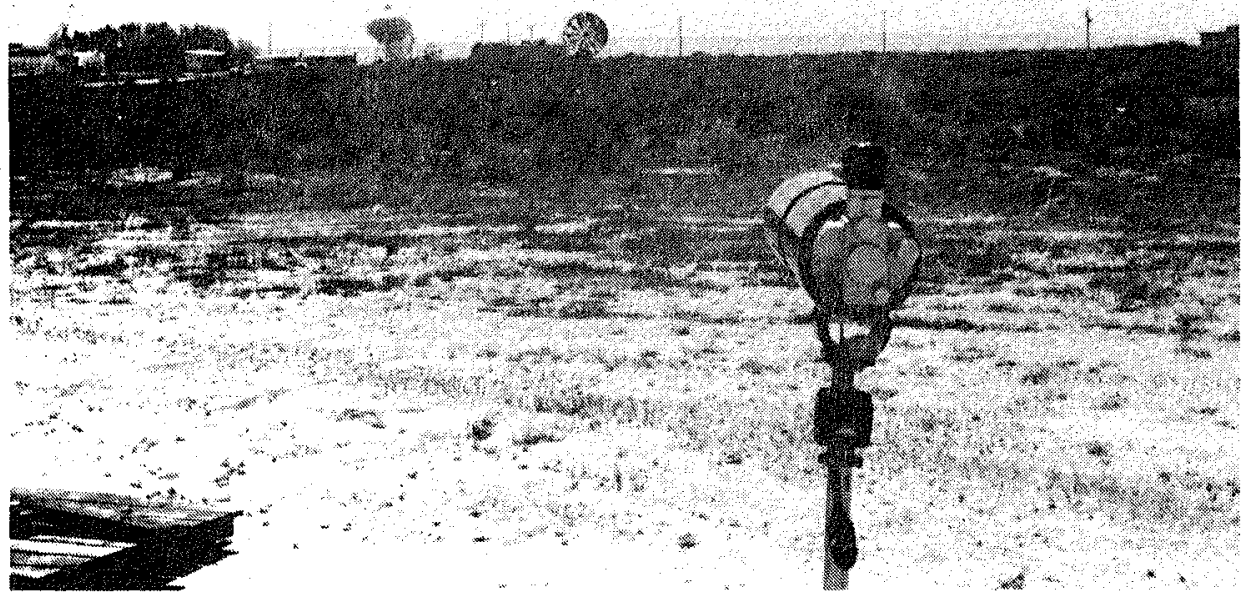

(b) Telescope Located $600 \mathrm{~m}$ from Concentrator

Figure 4-1. Setup for Diagnostic Testing of PDC-1 

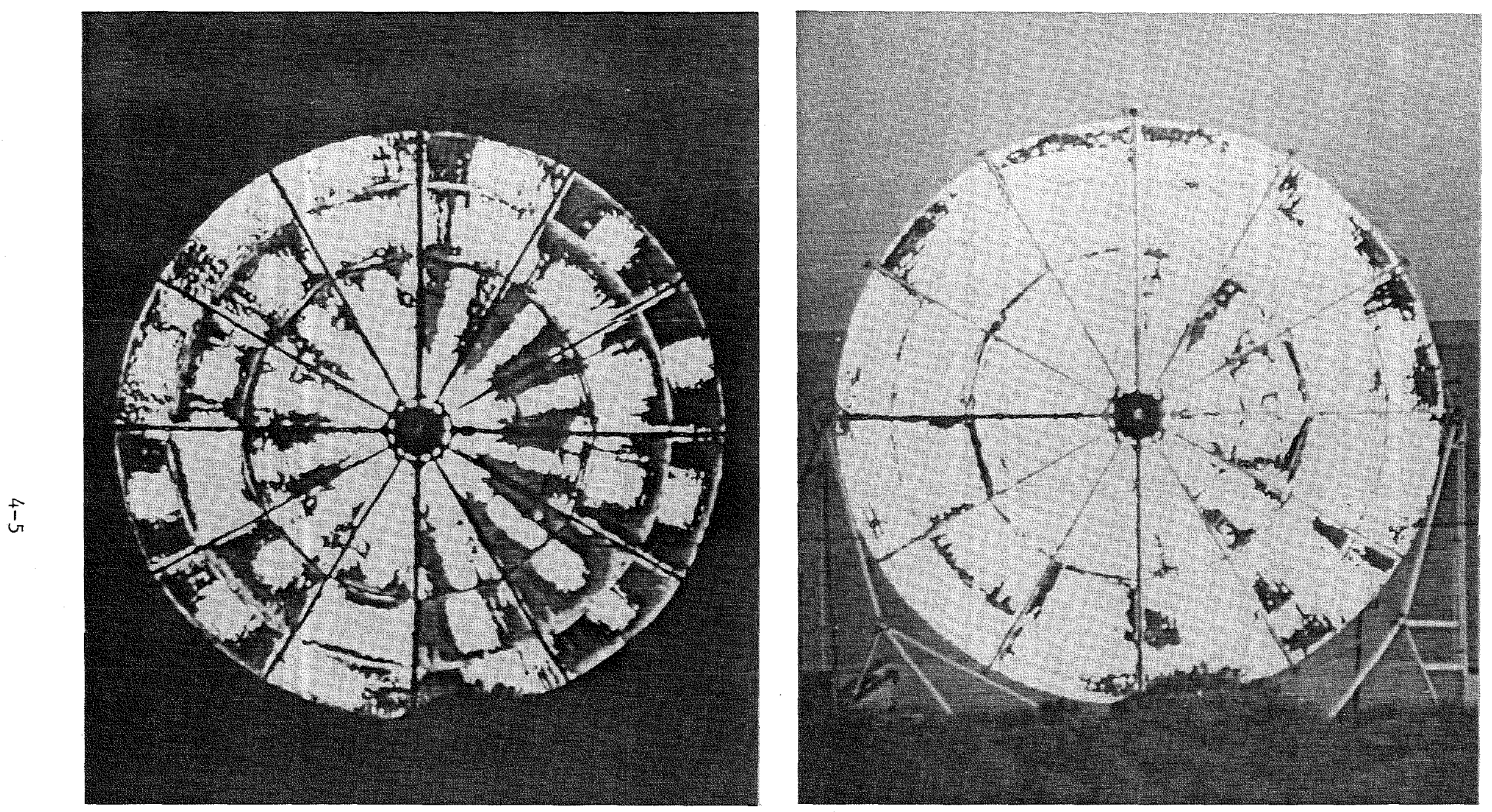

Figure 4-2. Diagnostic Photographs of PDC-1. (The left image is at an ambient temperature of $1.67^{\circ} \mathrm{C}\left(35^{\circ} \mathrm{F}\right)$ and the right image at $18.3^{\circ} \mathrm{C}\left(65^{\circ} \mathrm{F}\right)$. The white areas indicate regions of the reflecting panels forming an image smaller than $15 \mathrm{~cm}$ (6 in.) in diameter. The dark areas indicate panel areas forming images up to $38 \mathrm{~cm}$ (15 in.) in diameter from the colored parts of the focal plane target.)

(See color insert on following page.) 
less than the 0.98 that was measured by the point source tests. Analysis of the optics showed that this could not have been the result of the testing methods. Thermocouple measurements of the reflecting panels showed that the thermal gradient through the panels rose slowly to at least $10^{\circ} \mathrm{C}\left(18^{\circ} \mathrm{F}\right)$ at the same time that the calorimeter power values decreased. A review of the image degradation predicted by the optical analysis of the NASTRAN model data showed that thermal gradients through the panels could be significant. Termination of the parabolic dish project at JPL precluded a definitive evaluation of this effect and a search for a solution to the problem.

Upon completion of optical and characterization testing, PDC-1 was disassembled. The entire system and most of the other PDC-1 development test equipment was shipped to Sandia National Laboratories in Albuquerque, New Mexico, on May 16, 1984.

\section{F. CONCLUSION}

Optical testing during the development of PDC-1 demonstrated that panel image measurements and analysis could be used to give a useful prediction of the assembled concentrator performance. The testing methods were effective in locating the source of image errors resulting from an incorrect panel installation procedure. Finally, the testing project resulted in an improved understanding of the requirements for future optical models of point-focusing solar concentrators. 


\section{SECTION $V$ \\ REFERENCE}

1. Dennison, E.W., John, S.L., and Trentelman, G.F., Concentrator Optical Characterization Using Computer Mathematical Modelling and Point Source Testing, DOE/JPL-1060-77, JPL Publication 84-75, September 15, 1984 .

«U. S. GOVERNMENT PRINTING OFFICE: 1985-544-063//1047 
End of Document 